\title{
THE VALUE OF INFORMATION SHARING IN A DUAL-CHANNEL CLOSED-LOOP SUPPLY CHAIN
}

\author{
YAnting Huang ${ }^{1, *}$, Benrong ZhenG ${ }^{2}$ And Zonguun WAnG ${ }^{3}$
}

\begin{abstract}
This paper considers a dual-channel closed-loop supply chain consisting of a manufacturer, a retailer and a collector in which the retailer possesses private demand information and determines whether to share his private information with other chain members. Specifically, we develop four information sharing models, namely no information sharing (Model $\mathrm{C}-\mathrm{R}$ ), the retailer sharing information with the manufacturer (Model $\mathrm{C}-\mathrm{R}-\mathrm{M}$ ), the retailer revealing information to the collector (Model $\mathrm{C}-\mathrm{R}-\mathrm{C}$ ), and the retailer disclosing information to both the manufacturer and the collector (Model $\mathrm{C}-\mathrm{R}-\mathrm{T})$. We adopt the Stackelberg game to acquire the equilibrium strategies and examine the value of information sharing on chain members' decisions. We find that, chain members will set the largest wholesale price, retail prices of direct and indirect channels when the retailer only shares information with the manufacturer and the highest return rate can be obtained in the case of the retailer only revealing information to the collector. We can also find that, information sharing is profitable to the manufacturer and the collector, while is detrimental to the retailer. The manufacturer, the collector and the retailer can reach the largest profits in Model $\mathrm{C}-\mathrm{R}-\mathrm{T}$, Model $\mathrm{C}-\mathrm{R}-\mathrm{C}$ and Model $\mathrm{C}-\mathrm{R}-\mathrm{M}$, respectively.
\end{abstract}

Mathematics Subject Classification. 90C05, 90B05.

Received October 19, 2020. Accepted June 1, 2021.

\section{INTRODUCTION}

In the past several decades, closed-loop supply chains (CLSCs), which contain both the forward channel and the reverse channel, have been widely investigated in literature and practice. Basically, the reverse channel involves the following processes: collecting used products from consumers, reprocessing returned products/components, and selling remanufactured products $[16,28,36]$. Remanufacturing is recovery process that upgrades a used product to like-new condition, with benefits that include reduced waste pollution and landfill space, and earned companies' economic profitability [11,21,23]. Examples of such remanufacturing include many industrial products such as automobile engines, electrical and electronic equipment, single-use cameras, etc. Related research has indicated that in the auto industry, remanufacturing a used part consumes less $20 \%$

Keywords. Supply chain management, remanufacturing, dual-channel, information sharing, game theory.

1 College of Management, Shenzhen University, 3688 Nanhai Ave, Shenzhen 518060, P.R. China.

2 School of Economics and Management, Huazhong Agricultural University, 1 Shizishan Road, Wuhan 430070, P.R. China.

3 School of Management, Huazhong University of Science and Technology, 1037 Luoyu Road,Wuhan 430074, P.R. China.

*Corresponding author: ythuang4028@163.com 
of the energy and raw material required to produce a new one $[5,37]$. Now it comes to a tricky question: who should conduct sales of new and remanufactured products?

In today's competitive environment, many enterprises face the channel selection decision of whether to add a direct channel to their distribution channel $[4,5]$. On one hand, the direct channel, where the manufacturer interacts with consumers directly, can help the manufacturer to restrict retailers' bargaining power. On the other hand, the indirect channel (i.e., traditional retail channel), where the manufacturer adopts retailers to reach final consumers, can offer offline customer experience and product service support to cultivate the brand effect. According to a survey, more than $42 \%$ of top suppliers distribute their products through an online-offline channel [9]. And the computer manufacturers such as IBM and Dell have already adopted two channels to sell their products, namely retail outlets and mail order. Related research shows that the dual-distribution channel is more efficient than a single-distribution channel and the dual-distribution channel can increase product demand and firms' profitability [29]. The topic of dual-distribution channel has received considerable attention in supply chain management.

Conventionally, most research about dual-channel supply chain is based on the assumption of information symmetry, and considers that chain members obtain the complete information $[8,18]$. This seems to deviates from the real life. In some cases, the retailer, who is near to the market, usually has access to private market demand information, and other chain members has no idea about this information [24,33]. As an example, a famous electronics supplier Solectron suffers a huge profit loss because of $\$ 4.7$ billion excess inventory resulting from a lack of accurate market demand information [3,12,41]. Such information asymmetry will affect firms' efficiency and profitability $[13,14]$. In this case, the retailer endowed with private information often makes his information publicly available, and then the manufacturer can better understand the market and make informed decisions after receiving the retailer's demand information. The above illustrates that information sharing plays an irreplaceable role on improving the overall supply chain performance and firms' economic interests.

Although some research on information sharing has been implemented in a closed-loop system, the case of inserting information sharing into a dual-channel CLSC has not yet been investigated. To fill this gap, we in this paper assume that the retailer possesses private demand information and decides whether to share information with the manufacturer and the collector. We analyze the value of information sharing in a CLSC where both the manufacturer and the retailer undertake selling products through direct and indirect channels, respectively. Specifically, we develop four information sharing models under hybrid distribution channel: (1) no information sharing, (2) the retailer sharing information with the manufacturer, (3) the retailer disclosing information to the collector, and (4) the retailer revealing information to both the manufacturer and the collector. We aim to solve the following questions:

(1) What are the equilibrium strategies of each model in the dual-channel CLSC?

(2) From the view of each chain member, which is the optimal information sharing pattern?

(3) How does information sharing affect chain members' pricing decisions?

The rest of this paper is organized as follows. Related literature is presented in Section 2. Section 3 describes model assumptions and notation. Based on Section 3, we develop and address four information sharing models in Section 4. We further compare four models with respect to pricing decisions and profits of chain members in Section 5. Section 6 conducts numerical examples. The last Section concludes. Proofs are provided in appendix A.

\section{Literature REVIEW}

The first stream of research on remanufacturing is widely investigated in a closed-loop system. Savaskan et al. [32] first compare three collecting modes, namely manufacturer-collection, retailer-collection and thirdparty collection. In their research, the retailer-collection mode can bring the most profits for the manufacturer. By examining the role of channel power structure, Choi et al. [6] put forward three power structure models: manufacturer-led, retailer-led and collector-led, and suggest that retailer-led is the optimal model for the supply 
chain. Atasu et al. [2] discuss how collection cost structure affect the manufacturer's reverse channel choice and show that if cost structure allows the manufacturer incentivize the retailer to increase product sales, the retailer-managed collection dominates manufacturer-managed collection for the manufacturer. Subsequently, De Giovanni et al. [10] evaluate the effect of incentive strategies on the CLSC and confirm that incentive strategies can achieve supply chain coordination. Miao et al. [27] examine trade-in strategy in the centralized collection, retailer-collection and manufacturer-collection modes and indicate that, when the net value of used product is sufficiently high, the trade-in strategy can boost product demand and chain members' profits.

The above research analyzes the case where the retailer is responsible for product sales in a single-distribution channel, the dual-distribution channel CLSC is also deserved investigation. Ma et al. [26] investigate the role of government subsidy when the retailer and the e-tailer sell products concurrently. They suggest that both the manufacturer and the retailer can benefit from the government subsidy. Saha et al. [30] propose a rewarddriven policy in a dual-channel CLSC. In their models, the remanufacturing rate can reach the largest when the manufacturer undertakes collection activities. Similarly, Xie et al. [39] develop a revenue-sharing mechanism when there exist online/offline dual channel, and emphasize the effect of cooperation advertising on the CLSC. Considering dual-distribution and dual-recycling channels simultaneously, Giri et al. [15] explore how different channel power structures affect pricing and collection decisions, and demonstrate that the retailer-led mode is the most effective mode for the whole supply chain. These studies investigate chain members' pricing and collection strategies in a dual-channel CLSC. However, scarce research examines the value of information sharing in a CLSC. This paper combines information sharing with remanufacturing, and analyze the value of information sharing when the manufacturer and the retailer concurrently undertake the sales of products in a dual-channel CLSC.

In the second stream, most literature focuses on how information sharing affects chain members' pricing strategies in a forward supply chain. Li [25] analyzes "direct effect" and "indirect effect" of information sharing in a two-level supply chain. Yue et al. [40] make a comparison between "make-to-order" and "make-to-stock" scenarios in a dual-channel supply chain, and find that information sharing is profitable to both the manufacturer and the retailer in "make-to-stock" scenario. While in "make-to-order" scenario, the manufacturer can always benefit from information sharing, and information sharing can bring more profits to the retailer only if the manufacturer's forecast is high enough. Regarding information sharing in a competitive supply chain, Shang et al. [35] delineate the case where two competing manufacturers offers substitutable products to a retailer, and demonstrate that whether the retailer will share information with other chain members is contingent on product cost, competition intensity and contract mechanism. Shamir and Shin [34] also study the motivation of a retailer revealing information, and confirm that information sharing always plays a positive impact on both chain members and consumers. Subsequently, we turn to consider the value of information sharing into a CLSC, Hosoda et al. [17] explore how product returns information affects the CLSC performance, and show that the value of information depends on lead times, random yields and the parameters on product returns. Wang et al. [38] analyze the case where the retailer shares the collection effort level with the manufacturer under information screening contract. Their research indicates that a reward-penalty mechanism can promote the manufacturer to reduce wholesale price and increase buy-back price. Recently, Huang and Wang [19] evaluate the effect of information sharing when the manufacturer license other chain members to undertake remanufacturing activities, and suggest that information sharing is always profitable to the manufacturer. The above research has investigated the value of information sharing in single channel supply chain and also explored remanufacturing scenarios with competition. Differently, this paper investigates the value of information sharing in a dual-channel CLSC.

The contributions of this research are in two ways. Firstly, this paper analyzes how information sharing affects chain members' pricing decisions and profits in a closed-loop system. The results show that information sharing brings a profit loss to the retailer and a profit increase to the manufacturer only if the retailer shares information with the manufacturer. Secondly, the work examines which is the better remanufacturing strategy for each chain member. It is found that, the retailer obtains the largest profit in the case of no information sharing, the collector 


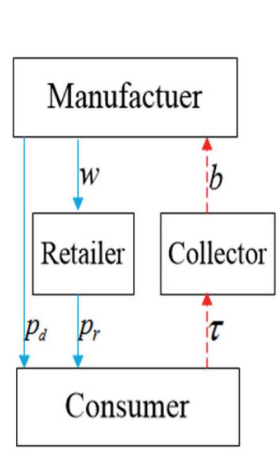

(a) Model C-R

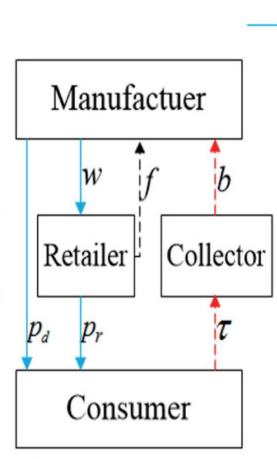

(b) Model C-R-M

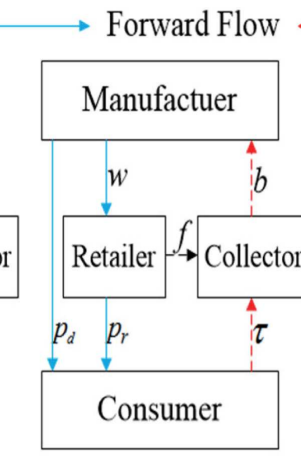

(c) Model C-R-C
Reverse Flow

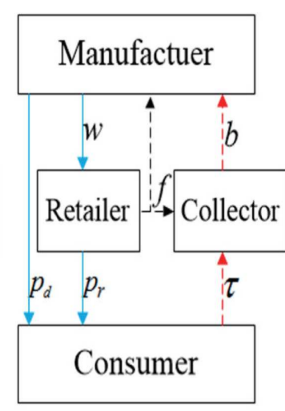

(d) Model C-R-T

FiguRE 1. Closed-loop supply chain models with remanufacturing.

prefers the case of the retailer only shares information with the collector, and the manufacturer's profit can reach the largest when the retailer simultaneously shares information with the manufacturer and the collector.

\section{Assumptions And notation}

We investigate a CLSC consisting of a manufacturer, a retailer and a collector where the retailer decides whether to share information with other chain members. Considering their roles in the closed-loop system, the manufacturer undertakes production of new and remanufactured products, and sells products to consumers through direct channel. The retailer conducts product sales through indirect channel, and the collector is engaged in collection activities. Additionally, we present four information sharing models, namely no information sharing (Model C-R, Fig. 1a), the retailer sharing information with the manufacturer (Model C-R-M, Fig. 1b), the retailer revealing information to the collector (Model $\mathrm{C}-\mathrm{R}-\mathrm{C}$, Fig. 1c), and the retailer sharing information with both the manufacturer and the collector (Model C-R-T, Fig. 1d).

Related parameters and notation are described in Table 1 . Moreover, $\Pi_{i}^{m}$ denotes the profit function for channel member $i$ in Model $m$. The superscript takes the value of Model $\mathrm{C}-\mathrm{R}, \mathrm{C}-\mathrm{R}-\mathrm{M}, \mathrm{C}-\mathrm{R}-\mathrm{C}, \mathrm{C}-\mathrm{R}-\mathrm{T}$ representing no information sharing, the retailer sharing information with the manufacturer, the collector and both the manufacturer and the collector, respectively. Here the subscript takes the value of M, R, and C, which represent the parameter corresponding to the manufacturer, the retailer and the collector, respectively. $\Delta E\left(\Pi_{i}^{j}\right)$ denotes the profit increase from information sharing for chain member $i$ in Model $j$ and the superscript $j$ takes the value of Model C-R-M, C-R-C, C-R-T. $\Delta E\left(\Pi_{i}^{j}\right)$ equals the difference between the expected profits for chain member in Model $j$ and Model $\mathrm{C}-\mathrm{R}\left(e . g ., \Delta E\left(\Pi_{M}^{\mathrm{C}-\mathrm{R}-\mathrm{M}}\right)=E\left(\Pi_{M}^{\mathrm{C}-\mathrm{R}-\mathrm{M}}\right)-E\left(\Pi_{M}^{\mathrm{C}-\mathrm{R}}\right)\right)$.

We consider that the production cost of a remanufactured product is lower than that of a new one, and $\Delta=c_{n}-c_{r}$, this assumption is widely adopted in literature [31]. Similar to Park and Keh [29], assume that the market demands of direct channel and indirect channel are in the following:

$$
D_{r}=a-\beta p_{r}+\gamma\left(p_{d}-p_{r}\right) \text { and } D_{d}=\gamma\left(p_{r}-p_{d}\right) .
$$

Here, $\beta$ and $\gamma$ represent the retailer's cross-price sensitivity and the difference between the retailer's pure price sensitivity after considering cross-price sensitivity, respectively. And the total market demand is a linear function of the retail price $\left(p_{r}\right)$ and is given by $D=D_{r}+D_{d}=a-\beta p_{r}$.

Additionally, we assume that random variable a represents the market potential size and $a=a_{0}+e$. Herein, $a_{0}$ is the certain part of market size and random variable $e$ is the uncertainty of market size with zero mean and variance $k$. The retailer can observe a demand signal $f=a+\varepsilon$, which captures market demand information. 
TABLE 1. Notations and definitions.

\begin{tabular}{ll}
\hline \hline Notations & Definitions \\
\hline Parameters & \\
$c_{n}$ & The average unit cost of manufacturing new products \\
$c_{r}$ & The average unit cost of manufacturing returned products \\
$a$ & The market size \\
$A$ & The demand forecast value \\
$\Delta$ & The average unit cost saving from remanufacturing \\
$b$ & The unit transfer price of a returned product given by the manufacturer to the collector \\
$a_{0}$ & The certain part of market size \\
$e$ & The uncertain part of market size \\
$f$ & Demand signal \\
$\varepsilon$ & The error term of demand signal \\
$k$ & The variance of random variable $e$ \\
$\theta$ & The variance of random variable $\varepsilon$ \\
$I$ & The investment of collection activities \\
$C_{L}$ & Scale parameter, the exchanging coefficient between the collection rate and the investment \\
\hline Decision variables \\
$w$ & The unit wholesale price \\
$p_{d}$ & The unit retail price of direct channel \\
$p_{r}$ & The unit retail price of indirect channel \\
$D$ & The total market demand \\
$D_{r}$ & The market demand of direct channel \\
$D_{d}$ & The market demand of indirect channels \\
$\tau$ & The return rate of a used product \\
$\Pi$ & Profit \\
\hline
\end{tabular}

The random variable $\varepsilon$ is an error term with zero mean and variance $\theta$, and $e$ and $\varepsilon$ are independent. Analogous to the work by $\mathrm{Li}$ [20], the information structure can be described as follows:

$$
E(a \mid f)=\frac{\theta}{k+\theta} a_{0}+\frac{k}{k+\theta} f \equiv A \text { and } E\left(\left(f-a_{0}\right)^{2}\right)=k+\theta .
$$

Define $t=k /(k+\theta)$ as demand forecast accuracy of the retailer, and $0 \leq t \leq 1$. If $t=1$ holds, the demand forecast value $(A)$ and the actual value $(a)$ are the same. While if $t=0$ is satisfied, the demand forecast value $(A)$ and the actual value $(a)$ have a significant difference.

According to the research of Choi et al. [6] and Huang et al. [1], assume that all returned products can be remanufactured and resold successfully. And there is no different between new and remanufactured products. In practice, the remanufactured and new cameras can perfect substitute in Kodak company [7]. The manufacturer, as the channel leader, has sufficient power over the retailer and the collector in the CLSC.

\section{Closed-Loop Supply Chain Models With information SHARING}

The primary goal of this paper is to investigate the effect of information sharing on chain members' pricing decisions and profits. To this end, we assume that the retailer possesses private market demand information and shares information with the manufacturer, the collector and both the manufacturer and the collector, respectively. The game order is that the manufacturer first determines the wholesale price $w$, the retail price of direct channel $p_{r}$ and the transfer price $b$. And then the retailer and the collector decide the retail price of indirect channel $p_{d}$ and the return rate of used products $\tau$, respectively. 


\subsection{No information sharing(Model $\mathbf{C}-\mathbf{R})$}

The no information sharing scenario provides a benchmark to compare with information sharing models. Since the retailer does not reveal information to other chain members in Model $\mathrm{C}-\mathrm{R}$, the optimal profit functions of chain members can be expressed as follows:

$$
\begin{aligned}
\operatorname{Max}_{w, p_{d}} E\left(\Pi_{M}^{\mathrm{C}-\mathrm{R}}\right) & =E\left(w D_{r}+p_{d} D_{d}-\left(c_{n}-\tau(\Delta-b)\right)\left(D_{r}+D_{d}\right)\right) \\
& =E\left(w\left(a-\beta p_{r}+\gamma\left(p_{d}-p_{r}\right)\right)+p_{d} \gamma\left(p_{r}-p_{d}\right)-\left(c_{n}-\tau(\Delta-b)\right)\left(a-\beta p_{r}\right)\right) \\
\operatorname{Max}_{p_{r}} E\left(\Pi_{R}^{\mathrm{C}-\mathrm{R}}\right) & =E\left(\left(p_{r}-w\right)\left(A-\beta p_{r}+\gamma\left(p_{d}-p_{r}\right)\right) \mid f\right) \\
\operatorname{Max}_{\tau} E\left(\Pi_{C}^{\mathrm{C}-\mathrm{R}}\right) & =E\left(b \tau\left(a-\beta p_{r}\right)-C_{L} \tau^{2}\right)
\end{aligned}
$$

From first-order conditions, we can obtain the optimal retail price of indirect channel $p_{r}^{\mathrm{C}-\mathrm{R}^{*}}=$ $\left[A+\gamma p_{d}+(\beta+\gamma) w\right] / 2(\beta+\gamma)$. As there is no information sharing in Model $\mathrm{C}-\mathrm{R}$, the expected retail price of indirect channel for the manufacturer and the collector is $p_{r}^{\mathrm{C}-\mathrm{R}^{*}}=\left[a_{0}+\gamma p_{d}+(\beta+\gamma) w\right] / 2(\beta+\gamma)$. Herein, the superscript "** denotes the equilibrium value and the superscript "**" represents the expected value for chain members who does not receive demand information from the retailer.

Definition 4.1. Let $w^{\mathrm{C}-\mathrm{R}^{*}}$ be the equilibrium wholesale price in Model $\mathrm{C}-\mathrm{R}, p_{d}^{\mathrm{C}-\mathrm{R}^{*}}$ be the equilibrium retail price of direct channel in Model $\mathrm{C}-\mathrm{R}, \tau^{\mathrm{C}-\mathrm{R}^{*}}$ be the equilibrium return rate of used products in Model $\mathrm{C}-\mathrm{R}$. $E\left(\Pi_{M}^{\mathrm{C}-\mathrm{R}^{*}}\right), E\left(\Pi_{R}^{\mathrm{C}-\mathrm{R}^{*}}\right)$ and $E\left(\Pi_{C}^{\mathrm{C}-\mathrm{R}^{*}}\right)$ are defined as the equilibrium profits of the manufacturer, the retailer and the collector, respectively.

Then we get the equilibrium decisions by using backward induction and the results are presented in Proposition 4.2 .

Proposition 4.2. In Model $C$-R, the optimal policies can be characterized as follows.

$$
\begin{aligned}
w^{\mathrm{C}-\mathrm{R}^{*}} & =\frac{\left[2 C_{L}(\beta+\gamma)-(\Delta-b)(\beta+2 \gamma) b \beta\right] a_{0}+2 C_{L}(\beta+\gamma) \beta c_{n}}{\beta\left[4 C_{L}(\beta+\gamma)-(\Delta-b) b \beta(\beta+2 \gamma)\right]} \\
p_{d}^{\mathrm{C}-\mathrm{R}^{*}} & =\frac{\left[2 C_{L}(\beta+\gamma)-(\Delta-b)(\beta+2 \gamma) b \beta\right] a_{0}+2 C_{L}(\beta+\gamma) \beta c_{n}}{\beta\left[4 C_{L}(\beta+\gamma)-(\Delta-b) b \beta(\beta+2 \gamma)\right]} \\
\tau^{\mathrm{C}-\mathrm{R}^{*}} & =\frac{b(\beta+2 \gamma)\left(a_{0}-\beta c_{n}\right)}{2\left[4 C_{L}(\beta+\gamma)-(\Delta-b) b \beta(\beta+2 \gamma)\right]} .
\end{aligned}
$$

Putting the values of the parameters back into Eqs. (4.1)-(4.3) and simplifying, we acquire the optimal profits of chain members in the following:

$$
\begin{aligned}
& E\left(\Pi_{M}^{\mathrm{C}-\mathrm{R}^{*}}\right)=\frac{C_{L}(\beta+2 \gamma)\left(a_{0}-\beta c_{n}\right)^{2}}{2 \beta\left[4 C_{L}(\beta+\gamma)-(\Delta-b) b \beta(\beta+2 \gamma)\right]} \\
& E\left(\Pi_{R}^{\mathrm{C}-\mathrm{R}^{*}}\right)=\frac{k t}{4(\beta+\gamma)}+\frac{C_{L}^{2}(\beta+\gamma)\left(a_{0}-\beta c_{n}\right)^{2}}{\left[4 C_{L}(\beta+\gamma)-(\Delta-b) b \beta(\beta+2 \gamma)\right]^{2}} \\
& E\left(\Pi_{C}^{\mathrm{C}-\mathrm{R}^{*}}\right)=\frac{C_{L} b^{2}(\beta+2 \gamma)^{2}\left(a_{0}-\beta c_{n}\right)^{2}}{4\left[4 C_{L}(\beta+\gamma)-(\Delta-b) b \beta(\beta+2 \gamma)\right]^{2}} .
\end{aligned}
$$

Subsequently, taking the first-order condition of $E\left(\Pi_{M}^{\mathrm{C}-\mathrm{R}^{*}}\right)$ with respect to $b$, we can obtain that the manufacturer's profit can realize maximization when $b^{\mathrm{C}-\mathrm{R}^{*}}=\Delta / 2$, and we summarize the optimal results in the Appendix (Tab. A.1-A.3). 


\subsection{The retailer sharing information with the manufacturer (Model $C-R-M$ )}

In Model $\mathrm{C}-\mathrm{R}-\mathrm{M}$, the retailer chooses to share information with the manufacturer, the optimal expected profits of chain members can be defined as follows:

$$
\begin{aligned}
\operatorname{Max}_{w} E\left(\prod_{d}^{\mathrm{C}-\mathrm{R}-\mathrm{M}}\right) & =E\left(w D_{r}+p_{d} D_{d}-\left(c_{n}-\tau(\Delta-b)\right)\left(D_{r}+D_{d}\right) \mid f\right) \\
& =E\left(w\left(A-\beta p_{r}+\gamma\left(p_{d}-p_{r}\right)\right)+p_{d} \gamma\left(p_{r}-p_{d}\right)-\left(c_{n}-\tau(\Delta-b)\left(A-\beta p_{r}\right) \mid f\right)\right. \\
\operatorname{Max}_{p_{r}} E\left(\Pi_{R}^{\mathrm{C}-\mathrm{R}-\mathrm{M}}\right) & =E\left(\left(p_{r}-w\right)\left(A-\beta p_{r}+\gamma\left(p_{d}-p_{r}\right)\right) \mid f\right) \\
\operatorname{Max}_{\tau} E\left(\Pi_{C}^{\mathrm{C}-\mathrm{R}-\mathrm{M}}\right) & =E\left(b \tau\left(a-\beta p_{r}\right)-C_{L} \tau^{2}\right) .
\end{aligned}
$$

The optimal retail price of indirect channel can be given by $p_{r}^{\mathrm{C}-\mathrm{R}-\mathrm{M}^{*}}=\left[A+\gamma p_{d}+(\beta+\gamma) w\right] / 2(\beta+\gamma)$. The expected retail price for the collector is $p_{r}^{\mathrm{C}-\mathrm{R}-\mathrm{M}^{* *}}=\left[a_{0}+\gamma p_{d}+(\beta+\gamma) w\right] / 2(\beta+\gamma)$ because he does not receive the retailer's demand information.

Definition 4.3. Let $w^{\mathrm{C}-\mathrm{R}-\mathrm{M}^{*}}, p_{d}^{\mathrm{C}-\mathrm{R}-\mathrm{M}^{*}}, \tau^{\mathrm{C}-\mathrm{R}-\mathrm{M}^{*}}$ be the equilibrium wholesale price, retail price and return rate of used products in Model $\mathrm{C}-\mathrm{R}-\mathrm{M}$, respectively. $E\left(\Pi_{M}^{\mathrm{C}-\mathrm{R}-\mathrm{M}^{*}}\right), E\left(\Pi_{R}^{\mathrm{C}-\mathrm{R}-\mathrm{M}^{*}}\right)$ and $E\left(\Pi_{C}^{\mathrm{C}-\mathrm{R}-\mathrm{M}^{*}}\right)$ are defined as the equilibrium profits of the manufacturer, the retailer and the collector in Model $\mathrm{C}-\mathrm{R}-\mathrm{M}$, respectively.

Proposition 4.4. In Model $C-R-M$, the optimal policies can be characterized as follows:

$$
\begin{aligned}
w^{\mathrm{C}-\mathrm{R}-\mathrm{M}^{*}} & =\frac{\left[4 C_{L}(\beta+\gamma)-(\Delta-b)(\beta+2 \gamma) b \beta\right] A-(\Delta-b)(\beta+2 \gamma) b \beta a_{0}+4 C_{L}(\beta+\gamma) \beta c_{n}}{2 \beta\left[4 C_{L}(\beta+\gamma)-(\Delta-b) \beta b(\beta+2 \gamma)\right]}, \\
p_{d}^{\mathrm{C}-\mathrm{R}-\mathrm{M}^{*}} & =\frac{\left[4 C_{L}(\beta+\gamma)-(\Delta-b)(\beta+2 \gamma) b \beta\right] A-(\Delta-b)(\beta+2 \gamma) b \beta a_{0}+4 C_{L}(\beta+\gamma) \beta c_{n}}{2 \beta\left[4 C_{L}(\beta+\gamma)-(\Delta-b) \beta b(\beta+2 \gamma)\right]} \\
\tau^{\mathrm{C}-\mathrm{R}-\mathrm{M}^{*}} & =\frac{b(\beta+2 \gamma)\left(a_{0}-\beta c_{n}\right)}{2\left[4 C_{L}(\beta+\gamma)-(\Delta-b) b \beta(\beta+2 \gamma)\right]} .
\end{aligned}
$$

Then we can attain the optimal expected profits by substituting $w^{\mathrm{C}-\mathrm{R}-\mathrm{M}^{*}}, p_{d}^{\mathrm{C}-\mathrm{R}-\mathrm{M}^{*}}$ and $\tau^{\mathrm{C}-\mathrm{R}-\mathrm{M}^{*}}$ into equations (4.4)-(4.6) in the following:

$$
\begin{aligned}
& E\left(\Pi_{M}^{\mathrm{C}-\mathrm{R}-\mathrm{M}^{*}}\right)=\frac{(\beta+2 \gamma) k t}{8 \beta(\beta+\gamma)}+\frac{C_{L}(\beta+2 \gamma)\left(a_{0}-\beta c_{n}\right)^{2}}{2 \beta\left[4 C_{L}(\beta+\gamma)-(\Delta-b) \beta b(\beta+2 \gamma)\right]}, \\
& E\left(\Pi_{R}^{\mathrm{C}-\mathrm{R}-\mathrm{M}^{*}}\right)=\frac{k t}{16(\beta+\gamma)}+\frac{C_{L}^{2}(\beta+\gamma)\left(a_{0}-\beta c_{n}\right)^{2}}{\left[4 C_{L}(\beta+\gamma)-(\Delta-b) \beta b(\beta+2 \gamma)\right]^{2}}, \\
& E\left(\Pi_{C}^{\mathrm{C}-\mathrm{R}-\mathrm{M}^{*}}\right)=\frac{b^{2}(\beta+2 \gamma)^{2} k t}{64 C_{L}(\beta+\gamma)^{2}}+\frac{C_{L} b^{2}(\beta+2 \gamma)^{2}\left(a_{0}-\beta c_{n}\right)^{2}}{4\left[4 C_{L}(\beta+\gamma)-(\Delta-b) \beta b(\beta+2 \gamma)\right]^{2}}
\end{aligned}
$$

Similar to Model $\mathrm{C}-\mathrm{R}$, the optimal transfer price $b$ in Model $\mathrm{C}-\mathrm{R}-\mathrm{M}$ can be attained by maximizing the manufacturer's profit, and the value is $b^{\mathrm{C}-\mathrm{R}-\mathrm{M}^{*}}=\Delta / 2$. The corresponding prices and profits are concluded in Appendix (Tab. A.1-A.3). 


\subsection{The retailer sharing information with the collector (Model $\mathbf{C}-\mathbf{R}-\mathbf{C}$ )}

In this model, the retailer only reveals demand information to the collector, and the manufacturer make pricing decisions based on his own judgment. The chain members' problem can be solved in the following:

$$
\begin{aligned}
\operatorname{Max}_{w, p_{d}} E\left(\Pi_{M}^{\mathrm{C}-\mathrm{R}-\mathrm{C}}\right) & =E\left(w D_{r}+p_{d} D_{d}-\left(c_{n}-\tau(\Delta-b)\right)\left(D_{r}+D_{d}\right)\right) \\
& =E\left(w\left(a-\beta p_{r}+\gamma\left(p_{d}-p_{r}\right)\right)+p_{d} \gamma\left(p_{r}-p_{d}\right)-\left(c_{n}-\tau(\Delta-b)\right)\left(a-\beta p_{r}\right)\right) \\
\operatorname{Max}_{p_{r}} E\left(\Pi_{R}^{\mathrm{C}-\mathrm{R}-\mathrm{C}}\right) & =E\left(\left(p_{r}-w\right)\left(A-\beta p_{r}+\gamma\left(p_{d}-p_{r}\right)\right) \mid f\right) \\
\operatorname{Max}_{\tau} E\left(\Pi_{C}^{\mathrm{C}-\mathrm{R}-\mathrm{C}}\right) & =E\left(b \tau\left(A-\beta p_{r}\right)-C_{L} \tau^{2} \mid f\right) .
\end{aligned}
$$

In Model $\mathrm{C}-\mathrm{R}-\mathrm{C}$, the optimal retail price of indirect channel can be obtained by $p_{r}^{\mathrm{C}-\mathrm{R}-\mathrm{C}^{*}}=$ $\left[A+\gamma p_{d}+(\beta+\gamma) w\right] / 2(\beta+\gamma)$. Since the manufacturer doesn't receive demand information from the retailer, the expected retail price of indirect channel for the manufacturer is $p_{r}^{\mathrm{C}-\mathrm{R}-\mathrm{C}^{* *}}=\left[a_{0}+\gamma p_{d}+(\beta+\gamma) w\right] / 2(\beta+\gamma)$.

Definition 4.5. Define $w^{\mathrm{C}-\mathrm{R}-\mathrm{C}^{*}}, p_{d}^{\mathrm{C}-\mathrm{R}-\mathrm{C}^{*}}, \tau^{\mathrm{C}-\mathrm{R}-\mathrm{C}^{*}}$ as the equilibrium wholesale price, retail price and return rate of used products in Model $\mathrm{C}-\mathrm{R}-\mathrm{C}$, respectively. Let $E\left(\Pi_{M}^{\mathrm{C}-\mathrm{R}-\mathrm{C}^{*}}\right), E\left(\Pi_{R}^{\mathrm{C}-\mathrm{R}-\mathrm{C}^{*}}\right)$ and $E\left(\Pi_{C}^{\mathrm{C}-\mathrm{R}-\mathrm{C}^{*}}\right)$ be the equilibrium profits of the manufacturer, the retailer and the collector in Model $\mathrm{C}-\mathrm{R}-\mathrm{C}$, respectively.

Proposition 4.6. In Model $C-R-C$, the optimal policies can be characterized as follows:

$$
\begin{aligned}
w^{\mathrm{C}-\mathrm{R}-\mathrm{C}^{*}} & =\frac{\left[2 C_{L}(\beta+\gamma)-(\Delta-b)(\beta+2 \gamma) b \beta\right] a_{0}+2 C_{L}(\beta+\gamma) \beta c_{n}}{\beta\left[4 C_{L}(\beta+\gamma)-(\Delta-b) b \beta(\beta+2 \gamma)\right]} \\
p_{d}^{\mathrm{C}-\mathrm{R}-\mathrm{C}^{*}} & =\frac{\left[2 C_{L}(\beta+\gamma)-(\Delta-b)(\beta+2 \gamma) b \beta\right] a_{0}+2 C_{L}(\beta+\gamma) \beta c_{n}}{\beta\left[4 C_{L}(\beta+\gamma)-(\Delta-b) b \beta(\beta+2 \gamma)\right]} \\
\tau^{\mathrm{C}-\mathrm{R}-\mathrm{C}^{*}} & =\frac{b(\beta+2 \gamma)}{4 C_{L}(\beta+\gamma)}\left\{A-\frac{\left[2 C_{L}(\beta+\gamma)-(\Delta-b)(\beta+2 \gamma) b \beta\right] a_{0}+2 C_{L}(\beta+\gamma) \beta c_{n}}{\left[4 C_{L}(\beta+\gamma)-(\Delta-b) b \beta(\beta+2 \gamma)\right]}\right\} .
\end{aligned}
$$

By taking the values of the parameters into equations (4.7)-(4.9), the optimal results can be calculated in the following:

$$
\begin{aligned}
& E\left(\Pi_{M}^{\mathrm{C}-\mathrm{R}-\mathrm{C}^{*}}\right)=\frac{C_{L}(\beta+2 \gamma)\left(a_{0}-\beta c_{n}\right)^{2}}{2 \beta\left[4 C_{L}(\beta+\gamma)-(\Delta-b) b \beta(\beta+2 \gamma)\right]}, \\
& E\left(\Pi_{R}^{\left.\mathrm{C}-\mathrm{R}-\mathrm{C}^{*}\right)}=\frac{k t}{4(\beta+\gamma)}+\frac{C_{L}^{2}(\beta+\gamma)\left(a_{0}-\beta c_{n}\right)^{2}}{\left[4 C_{L}(\beta+\gamma)-(\Delta-b) b \beta(\beta+2 \gamma)\right]^{2}},\right. \\
& E\left(\Pi_{C}^{\mathrm{C}-\mathrm{R}-\mathrm{C}^{*}}\right)=\frac{b^{2}(\beta+2 \gamma)^{2} k t}{16 C_{L}(\beta+\gamma)^{2}}+\frac{C_{L} b^{2}(\beta+2 \gamma)^{2}\left(a_{0}-\beta c_{n}\right)^{2}}{4\left[4 C_{L}(\beta+\gamma)-(\Delta-b) b \beta(\beta+2 \gamma)\right]^{2}} .
\end{aligned}
$$

Afterward, we can find that the manufacturer can get the most profits when $b^{\mathrm{C}-\mathrm{R}-\mathrm{C}^{*}}=\Delta / 2$ holds. The optimal results can be attained by substituting $b^{\mathrm{C}-\mathrm{R}-\mathrm{C}^{*}}$, which are presented in Appendix B. 


\subsection{The retailer sharing information with both the manufacturer and the collector (Model C-R-T)}

In Model $\mathrm{C}-\mathrm{R}-\mathrm{T}$, the retailer prefers to make his private information publicly available, the optimal expected profits of the manufacturer, the retailer and the collector can be transformed into:

$$
\begin{aligned}
\operatorname{Max}_{w} E\left(\Pi_{M}^{\mathrm{C}-\mathrm{R}-\mathrm{T}}\right) & =E\left(w D_{r}+p_{d} D_{d}-\left(c_{n}-\tau(\Delta-b)\right)\left(D_{r}+D_{d}\right) \mid f\right) \\
& =E\left(w\left(A-\beta p_{r}+\gamma\left(p_{d}-p_{r}\right)\right)+p_{d} \gamma\left(p_{r}-p_{d}\right)-\left(c_{n}-\tau(\Delta-b)\right)\left(A-\beta p_{r}\right) \mid f\right) \\
\operatorname{Max}_{p_{r}} E\left(\Pi_{R}^{\mathrm{C}-\mathrm{R}-\mathrm{T}}\right) & =E\left(\left(p_{r}-w\right)\left(A-\beta p_{r}+\gamma\left(p_{d}-p_{r}\right)\right) \mid f\right) \\
\operatorname{Max}_{\tau} E\left(\Pi_{C}^{\mathrm{C}-\mathrm{R}-\mathrm{T}}\right) & =E\left(b \tau\left(A-\beta p_{r}\right)-C_{L} \tau^{2} \mid f\right)
\end{aligned}
$$

From first-order conditions, the optimal retail price of indirect channel can be expressed by $p_{r}^{\mathrm{C}-\mathrm{R}-\mathrm{T}^{*}}=$ $\left[A+\gamma p_{d}+(\beta+\gamma) w\right] / 2(\beta+\gamma)$ and the optimal prices and return rate are presented in Proposition 4.8.

Definition 4.7. $w^{\mathrm{C}-\mathrm{R}-\mathrm{T}^{*}}, p_{d}^{\mathrm{C}-\mathrm{R}-\mathrm{T}^{*}}, \tau^{\mathrm{C}-\mathrm{R}-\mathrm{T}^{*}}$ are defined as the equilibrium wholesale price, retail price and return rate of used products in Model $\mathrm{C}-\mathrm{R}-\mathrm{T}$, respectively. Let $E\left(\Pi_{M}^{\mathrm{C}-\mathrm{R}-\mathrm{T}^{*}}\right)$ be the equilibrium manufacturer's profit, $E\left(\Pi_{R}^{\mathrm{C}-\mathrm{R}-\mathrm{T}^{*}}\right)$ be the equilibrium retailer's profit, and $E\left(\Pi_{C}^{\mathrm{C}-\mathrm{R}-\mathrm{T}^{*}}\right)$ be the equilibrium collector's profit.

Proposition 4.8. In Model $C-R-T$, the optimal policies can be characterized as follows:

$$
\begin{aligned}
w^{\mathrm{C}-\mathrm{R}-\mathrm{T}^{*}} & =\frac{\left[2 C_{L}(\beta+\gamma)-(\Delta-b)(\beta+2 \gamma) b \beta\right] A+2 C_{L}(\beta+\gamma) \beta c_{n}}{\beta\left[4 C_{L}(\beta+\gamma)-(\Delta-b) b \beta(\beta+2 \gamma)\right]} \\
p_{d}^{\mathrm{C}-\mathrm{R}-\mathrm{T}^{*}} & =\frac{\left[2 C_{L}(\beta+\gamma)-(\Delta-b)(\beta+2 \gamma) b \beta\right] A+2 C_{L}(\beta+\gamma) \beta c_{n}}{\beta\left[4 C_{L}(\beta+\gamma)-(\Delta-b) b \beta(\beta+2 \gamma)\right]} \\
\tau^{\mathrm{C}-\mathrm{R}-\mathrm{T}^{*}} & =\frac{b(\beta+2 \gamma)\left(A-\beta c_{n}\right)}{2\left[4 C_{L}(\beta+\gamma)-(\Delta-b) b \beta(\beta+2 \gamma)\right]} .
\end{aligned}
$$

Then putting the parameters into equations (4.10)-(4.12), the optimal expected profits of chain members can be simplified as follows:

$$
\begin{aligned}
& E\left(\Pi_{M}^{\mathrm{C}-\mathrm{R}-\mathrm{T}^{*}}\right)=\frac{C_{L}(\beta+2 \gamma)\left[k t+\left(a_{0}-\beta c_{n}\right)^{2}\right]}{2 \beta\left[4 C_{L}(\beta+\gamma)-(\Delta-b) b \beta(\beta+2 \gamma)\right]}, \\
& E\left(\Pi_{R}^{\left.\mathrm{C}-\mathrm{R}-\mathrm{T}^{*}\right)}=\frac{C_{L}^{2}(\beta+\gamma)\left[k t+\left(a_{0}-\beta c_{n}\right)^{2}\right]}{\left[4 C_{L}(\beta+\gamma)-(\Delta-b) b \beta(\beta+2 \gamma)\right]^{2}},\right. \\
& E\left(\Pi_{C}^{\mathrm{C}-\mathrm{R}-\mathrm{T}^{*}}\right)=\frac{C_{L} b^{2}(\beta+2 \gamma)^{2}\left[k t+\left(a_{0}-\beta c_{n}\right)^{2}\right]}{4\left[4 C_{L}(\beta+\gamma)-(\Delta-b) b \beta(\beta+2 \gamma)\right]^{2}} .
\end{aligned}
$$

Taking the first-order condition of $E\left(\Pi_{M}^{\mathrm{C}-\mathrm{R}-\mathrm{T}^{*}}\right)$ with respect to $b$, we can get the optimal transfer price by maximizing the manufacturer's profit, the value can be calculated as $b^{\mathrm{C}-\mathrm{R}-\mathrm{T}^{*}}=\Delta / 2$. We can also obtain the optimal prices and profits by substituting $b^{\mathrm{C}-\mathrm{R}-\mathrm{T}^{*}}$ into the above equations, and the results are described in Appendix (Tab. A.1-A.3).

\section{AnAlysis of ClOSED-LOOP SUPPLy CHAin MODELS}

This section presents further analyzes based on the aforementioned models. In the first subsection, we investigate the effect of demand forecast value $(A)$ and demand forecast accuracy $(t)$ on the optimal pricing decisions. Next, we compare four information sharing models with respect to prices, quantities and profits. 
TABLE 2. Effect of parameters on the optimal solutions ( $\nearrow$ : increasing; $\searrow$ : decreasing; $\perp$ : constant).

\begin{tabular}{|c|c|c|c|}
\hline Model & $\mathrm{C}-\mathrm{R}-\mathrm{M}$ & $\mathrm{C}-\mathrm{R}-\mathrm{C}$ & $\mathrm{C}-\mathrm{R}-\mathrm{T}$ \\
\hline Parameter & \multicolumn{3}{|c|}{$A$ (Demand forecast value) } \\
\hline$w^{*}$ & $\perp$ & $\perp$ & $\nearrow$ \\
\hline$p_{d}^{*}$ & $\perp$ & $\perp$ & $\nearrow$ \\
\hline$p_{r}^{*}$ & $\nearrow$ & $\nearrow$ & $\nearrow$ \\
\hline$\tau^{*}$ & $\perp$ & $\nearrow$ & $\nearrow$ \\
\hline Parameter & \multicolumn{3}{|c|}{$t$ (Demand forecast accuracy) } \\
\hline$\Pi_{M}^{*}$ & $\perp$ & $\perp$ & $\nearrow$ \\
\hline$\Pi_{R}^{*}$ & $\nearrow$ & $\nearrow$ & $\nearrow$ \\
\hline$\Pi_{C}^{*}$ & $\perp$ & $\nearrow$ & $\nearrow$ \\
\hline
\end{tabular}

\subsection{The effect of information sharing}

As described from Table 2, the retail price of indirect channel is increasing with the increase of demand forecast value $(A)$ in all information sharing models. It can be explained that, the retailer would elevate retail price to obtain more revenues from marketing activities when he observes a larger market demand. As for the manufacturer and the collector, the impacts of information sharing on their pricing decisions are concluded in the following: (1) When the retailer chooses to conceal his demand information, the change of demand forecast value has no impact on their pricing decisions. (2) When the retailer only shares information with the manufacturer, the wholesale price and the retail price of direct channel will be raised by the manufacturer due to a larger market demand, while the return rate of used products has no change as the collector doesn't receive larger demand information. (3) When the retailer only reveals demand information to the collector, the collector will elevate return rate of used products as a respond to the demand information, and finally earn more profits from collection activities. In this case, the manufacturer doesn't change his pricing decisions due to lacking of demand information. And (4) once both the manufacturer and the collector receive the larger demand information, they will adjust pricing decisions based on the demand forecast value. As a result, the wholesale price, the retail prices and the return rate are increasing with the increase of demand forecast value.

Moreover, as the retailer can make better pricing decisions with a higher demand forecast accuracy $(t)$, he can obtain more revenues with the increase of demand forecast accuracy in each information sharing pattern. It can also be observed that the manufacturer and the collector's expected profits have no change with $t$ in no information sharing model. In information sharing models, the collector always obtains more profits with the increase of $t$. On one hand, the collector can set an appropriate return rate of used products when he receives the retailer's demand information. On the other hand, the collector, as the channel follower, can make better pricing decisions based on the manufacturer's decisions when the retailer only shares information with the manufacturer. As for the manufacturer, his profit will increase in demand forecast accuracy only if he obtains demand information from the retailer.

\subsection{Comparisons of four information sharing models}

Afterward, we make comparison of chain members' pricing decisions and profits in four sharing information models, the detailed analyses are presented in Corollaries 5.1-5.7.

Corollary 5.1. The equilibrium prices satisfy the following relationships: If $A>a_{0}$ holds, then $w^{\mathrm{C}-\mathrm{R}-\mathrm{M}^{*}}>$ $w^{\mathrm{C}-\mathrm{R}-\mathrm{T}^{*}}>w^{\mathrm{C}-\mathrm{R}-\mathrm{C}^{*}}=w^{c-R^{*}}, \quad p_{d}^{\mathrm{C}-\mathrm{R}-\mathrm{M}^{*}}>p_{d}^{\mathrm{C}-\mathrm{R}-\mathrm{T}^{*}}>p_{d}^{\mathrm{C}-\mathrm{R}-\mathrm{C}^{*}}=p_{d}^{\mathrm{C}-\mathrm{R}^{*}}$, and $p_{r}^{\mathrm{C}-\mathrm{R}-\mathrm{M}^{*}}>p_{r}^{\mathrm{C}-\mathrm{R}-\mathrm{T}^{*}}>$ $p_{r}^{\mathrm{C}-\mathrm{R}-\mathrm{C}^{*}}=p_{r}^{c-R^{*}}$ 
Corollary 5.1 shows that, when the demand forecast value is relatively large (i.e., $A>a_{0}$ ), the wholesale price in the case of information sharing is always larger than that in the case of no information sharing, and the wholesale price in Model $\mathrm{C}-\mathrm{R}-\mathrm{M}$ achieves the largest. When the manufacturer receives a larger demand information from the retailer, shared demand information allows the manufacturer to increase his wholesale price to obtain more revenues from selling activities. Comparing the wholesale prices in Model $\mathrm{C}-\mathrm{R}-\mathrm{M}$ and $\mathrm{C}-\mathrm{R}-\mathrm{T}$, the manufacturer will set a larger wholesale price when only he receives a larger demand information in Model $\mathrm{C}-\mathrm{R}-\mathrm{M}$. While if the retailer simultaneously shares information with both the manufacturer and the collector in Model $\mathrm{C}-\mathrm{R}-\mathrm{T}$, the collector has the incentive to elevate the return rate of used products. In this case, the manufacturer, as the channel leader, will set a smaller wholesale price to increase product demand in the forward flow, and eventually obtain more used products from the collector to remanufacture to extract more unit cost savings in the reverse flow. It should be also noted that, the wholesale price has a positive impact on the retail prices of direct and indirect channels. Therefore, the retail prices show the same trend with the wholesale price.

Corollary 5.2. The equilibrium demands satisfy the following relationships: If $A>a_{0}$ holds, then $D^{\mathrm{C}-\mathrm{R}-\mathrm{M}^{*}}<$ $D^{\mathrm{C}-\mathrm{R}-\mathrm{T}^{*}}<D^{\mathrm{C}-\mathrm{R}-\mathrm{C}^{*}}=D^{C-\beta^{*}}, \quad D_{r}^{\mathrm{C}-\mathrm{R}-\mathrm{M}^{*}}<D_{r}^{c-R-T^{*}}<D_{r}^{\mathrm{C}-\mathrm{R}-\mathrm{C}^{*}}=D_{r}^{c-R^{*}}$, and $D_{d}^{\mathrm{C}-\mathrm{R}-\mathrm{M}^{*}}<$ $D_{d}^{\mathrm{C}-\mathrm{R}-\mathrm{T}^{*}}<D_{d}^{\mathrm{C}-\mathrm{R}-\mathrm{C}^{*}}=D_{d}^{\mathrm{C}-\mathrm{R}^{*}}$.

As depicted from Corollary 5.2, if demand forecast value exceeds the certain demand (i.e., $A>a_{0}$ ), the demands in the case of the retailer sharing information with the manufacturer is the smallest and in the case of no information sharing reach the largest. The demand can be reduced because of a larger retail price, which is indicated in Corollary 5.1. Under this condition, consumers are unwilling to purchase more products with a larger retail price, and then the demands of direct and indirect channels will be decreased. Accordingly, the total product demand will become smaller. In other words, the retail prices of direct and indirect channels play a negative impact on the demands. A smaller retail price would result in a larger demand when only the collector receive the demand information.

Corollary 5.3. The return rate of used products satisfies the relations as follows: If $A>a_{0}$ holds, then $\tau^{\mathrm{C}-\mathrm{R}-\mathrm{C}^{*}}>\tau^{\mathrm{C}-\mathrm{R}-\mathrm{T}^{*}}>\tau^{\mathrm{C}-\mathrm{R}-\mathrm{M}^{*}}=\tau^{\mathrm{C}-\mathrm{R}^{*}}$.

Corollary 5.3 indicates the relations of return rate of used products in different information sharing models. It can be observed that, if the demand forecast value satisfies $A>a_{0}$, the return rate in the case where only the collector receives the demand information reaches the largest, and in the case where the collector doesn't obtain demand information is the smallest. When the collector receives a larger market demand from the retailer, he would make effort to recycle more used products to earn more profits from collection activities. Thus, the return rate of used products will be increased. Moreover, the return rate in Model $\mathrm{C}-\mathrm{R}-\mathrm{T}$ is smaller than that in Model $\mathrm{C}-\mathrm{R}-\mathrm{C}$. It can be understood that, when both the manufacturer and the collector receive demand information from the retailer, shared demand information makes the manufacturer to raise the wholesale price, and then the increased prices lead to the decreased demand. In this case, fewer used products will be recycled by the collector and a smaller return rate of used products will be achieved in Model $\mathrm{C}-\mathrm{R}-\mathrm{T}$.

Corollary 5.4. The equilibrium transfer prices satisfy the following relationships: $b^{\mathrm{C}-\mathrm{R}-\mathrm{T}^{*}}=b^{\mathrm{C}-\mathrm{R}-\mathrm{C}^{*}}=$ $b^{\mathrm{C}-\mathrm{R}-\mathrm{M}^{*}}=b^{\mathrm{C}-\mathrm{R}^{*}}$.

From Corollary 5.4, the introduction of information sharing does not affect the transfer price. The manufacturer needs to make tradeoff when he decides a transfer price to the collector. On one hand, a larger transfer price can stimulate the collector to invest more in collection activities, and result in a higher return rate of used products, and finally the manufacturer can get more unit cost savings from remanufacturing. On the other hand, the transfer price directly has a negative impact on the manufacturer's profit. A larger transfer price shows that the manufacturer has to pay more to the collector. As a result, the manufacturer will set the constant transfer prices in four information sharing models to pursue his own profit maximization. 
Corollary 5.5. The equilibrium expected profits of the retailer satisfy the relations as:

(i) $E\left(\Pi_{R}^{\mathrm{C}-\mathrm{R}-\mathrm{M}^{*}}\right)<E\left(\Pi_{R}^{\mathrm{C}-\mathrm{R}-\mathrm{T}^{*}}\right)<E\left(\Pi_{R}^{\mathrm{C}-\mathrm{R}-\mathrm{C}^{*}}\right)=E\left(\Pi_{R}^{\mathrm{C}-\mathrm{R}^{*}}\right)$

(ii) $\Delta E\left(\Pi_{R}^{\mathrm{C}-\mathrm{R}-\mathrm{M}^{*}}\right)<\Delta E\left(\Pi_{R}^{\mathrm{C}-\mathrm{R}-\mathrm{T}^{*}}\right)<\Delta E\left(\Pi_{R}^{\mathrm{C}-\mathrm{R}-\mathrm{C}^{*}}\right)=0$.

Corollary 5.5 clarifies that, the retailer suffers a profit loss when the retailer shares information with the manufacturer (i.e., with mere the manufacturer and both the manufacturer and the collector), and the retailer's profit is the smallest in the case where the retailer only reveals information to the manufacturer. When the retailer shares information with the manufacturer, the manufacturer will make better pricing decisions to maximum his own profit, the retailer's profit will be decreased due to a larger wholesale price and a smaller demand. Specifically, from Corollaries 5.1 and 5.2, the largest wholesale price and the smallest demand will be achieved in Model C-R-M. Therefore, the retailer suffers the largest profit loss when only the manufacturer receives demand information in Model C-R-M. To stimulate the retailer's information sharing behavior, it is necessary to put forward some induction policies to promote the operation of such supply chains, such as government subsidies and contract schemes with other chain members [17]. We can also find that the retailer's profit remains unchanged when the retailer only discloses information to the collector. In this case, the collector will decide the return rate of used products based on the retailer's demand information. However, the manufacturer doesn't change his pricing decisions due to lacking of demand information, and thus the retailer can obtain the equal profits in Model $\mathrm{C}-\mathrm{R}-\mathrm{C}$ and Model $\mathrm{C}-\mathrm{R}$.

Corollary 5.6. The equilibrium expected profits of the manufacturer satisfies the relations as follows:

(i) $E\left(\Pi_{M}^{\mathrm{C}-\mathrm{R}-\mathrm{T}^{*}}\right)>E\left(\Pi_{M}^{\mathrm{C}-\mathrm{R}-\mathrm{M}^{*}}\right)>E\left(\Pi_{M}^{\mathrm{C}-\mathrm{R}-\mathrm{C}^{*}}\right)=E\left(\Pi_{M}^{\mathrm{C}-\mathrm{R}^{*}}\right)$

(ii) $\Delta E\left(\Pi_{M}^{\mathrm{C}-\mathrm{R}-\mathrm{T}^{*}}\right)>\Delta E\left(\Pi_{M}^{\mathrm{C}-\mathrm{R}-\mathrm{M}^{*}}\right)>\Delta E\left(\Pi_{M}^{\mathrm{C}-\mathrm{R}-\mathrm{C}^{*}}\right)=0$.

Corollary 5.6 demonstrates that the manufacturer can always obtain a profit increase when he receives demand information from the retailer, and the case where the retailer shares information with both the manufacturer and the collector dominates the case where the retailer only reveals information to the manufacturer. When the retailer shares information with both the manufacturer and the collector, the collector has the incentive to invest more in collection activities, which leads to a higher return rate of used products. Subsequently, the manufacturer will set an appropriate wholesale price to make sure market demand and simultaneously acquire more used products from the collector to obtain more unit cost savings from remanufacturing, and eventually reach the maximum revenues from both the forward and reverse flows. Besides, since the manufacturer doesn't adjust his pricing decisions in the case of the retailer only disclosing information to the collector, the manufacturer's profit in Model $\mathrm{C}-\mathrm{R}-\mathrm{C}$ is equivalent to that in Model $\mathrm{C}-\mathrm{R}$.

Corollary 5.7. The equilibrium expected profits of the collector satisfy the relations:

(i) $E\left(\Pi_{C}^{\mathrm{C}-\mathrm{R}-\mathrm{C}^{*}}\right)>E\left(\Pi_{C}^{\mathrm{C}-\mathrm{R}-\mathrm{T}^{*}}\right)>E\left(\Pi_{C}^{\mathrm{C}-\mathrm{R}-\mathrm{M}^{*}}\right)>E\left(\Pi_{C}^{\mathrm{C}-\mathrm{R}^{*}}\right)$;

(ii) $\Delta E\left(\Pi_{C}^{\mathrm{C}-\mathrm{R}-\mathrm{C}^{*}}\right)>\Delta E\left(\Pi_{C}^{\mathrm{C}-\mathrm{R}-\mathrm{T}^{*}}\right)>\Delta E\left(\Pi_{C}^{\mathrm{C}-\mathrm{R}-\mathrm{M}^{*}}\right)>0$.

As illustrated from Corollary 5.7(i), information sharing behavior is beneficial for the collector no matter whom the retailer shares with. For one thing, if the retailer reveals demand information to the collector (i.e., to mere the collector and both the manufacturer and the collector), he can make better decisions based on shared demand information. For another thing, if the retailer only discloses information to the manufacturer, the collector, as the channel follower, can make his decisions according to the manufacturer's strategies. From Corollary 5.7(ii), it is found that, considering the collector's profit, the value of information sharing in Model $\mathrm{C}-\mathrm{R}-\mathrm{C}$ dominate that in Model $\mathrm{C}-\mathrm{R}-\mathrm{T}$ and Model $\mathrm{C}-\mathrm{R}-\mathrm{M}$. This phenomenon is caused by the highest return rate and relatively larger demand in Model $\mathrm{C}-\mathrm{R}-\mathrm{C}$, which are presented in Corollaries 5.2 and 5.3. Moreover, compared with Model $\mathrm{C}-\mathrm{R}-\mathrm{M}$, information sharing in Model $\mathrm{C}-\mathrm{R}-\mathrm{T}$ can bring a larger profit for the collector. It is because both the collector and the manufacturer can better make decisions when they receive demand information from the retailer. 


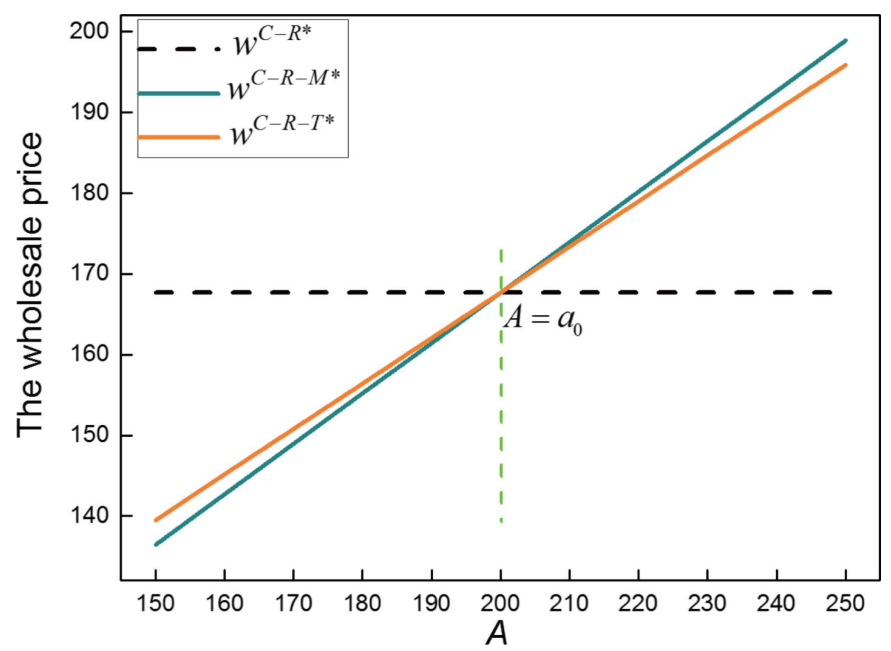

Figure 2. The wholesale price versus the demand forecast value $(A)$.

\section{Numerical EXAMPLeS}

This section further presents the numerical examples to compare four information sharing models with respect to equilibrium strategies, and analyzes how demand forecast value $(A)$ and demand forecast accuracy $(t)$ affect the optimal pricing decisions and profits of chain members. According to the research of Saha et al. [30], assuming that $a_{0}=200, \beta=0.8, \gamma=0.5, c_{n}=100, c_{r}=20, C_{L}=5000$ and $k=100$.

As clearly shown in Figure 2, the demand forecast value $(A)$ has no impact on the wholesale price $(w)$ in Model $\mathrm{C}-\mathrm{R}$ as the retailer doesn't share information with other chain members. When the retailer shares information with the manufacturer (i.e., Model $\mathrm{C}-\mathrm{R}-\mathrm{M}$ and Model $\mathrm{C}-\mathrm{R}-\mathrm{T}$ ), the wholesale prices are increasing with the increase of demand forecast value. And a larger wholesale price can be achieved in Model $\mathrm{C}-\mathrm{R}-\mathrm{M}$ than that in Model C-R-T when $A>a_{0}$ holds, which is consistent with Corollary 5.1. It can be explained that, the manufacturer will set a larger wholesale price to obtain more revenues after receiving a larger market demand from the retailer.

From Figure 3, in the case of no information sharing, the return rate of used products $(\tau)$ has no change with respect to different demand forecast value $(A)$. And the return rates in Model $\mathrm{C}-\mathrm{R}-\mathrm{C}$ and Model $\mathrm{C}-\mathrm{R}-\mathrm{T}$ are increasing in demand forecast value. With the increase of $A$, the collector prefers to invest more in collection activities, and results in a higher return rate of used products. Figure 3 also shows that, when the demand forecast value satisfies $A>a_{0}$, the return rate of used products will reach the largest in the case of the retailer only revealing information to the collector. In this case, the market demand and the wholesale price remain unchangeable because the manufacturer doesn't receive the demand information from the retailer. Therefore, the collector can increase the return rate of used products by investing more to recycle used products to obtain the largest profits in Model $\mathrm{C}-\mathrm{R}-\mathrm{C}$.

Figure 4 describes the change trend of the retailer's profit with different demand forecast accuracy $(t)$. Specifically, the demand forecast accuracy has a positive impact on the retailer's profit in all information sharing patterns. And the retailer obtains a smaller profit in Model $\mathrm{C}-\mathrm{R}-\mathrm{M}$ and Model $\mathrm{C}-\mathrm{R}-\mathrm{T}$ than that in Model C-R. Moreover, comparing with other information sharing modes, the retailer's profit in Model C- $\mathrm{R}-$ $\mathrm{M}$ is the smallest. When the manufacturer obtains the demand information from the retailer, he can make better pricing decisions and increase the wholesale price to earn more revenues, which results in a profit loss of the retailer. Such profit loss makes the retailer has no incentive to share his private information with other 


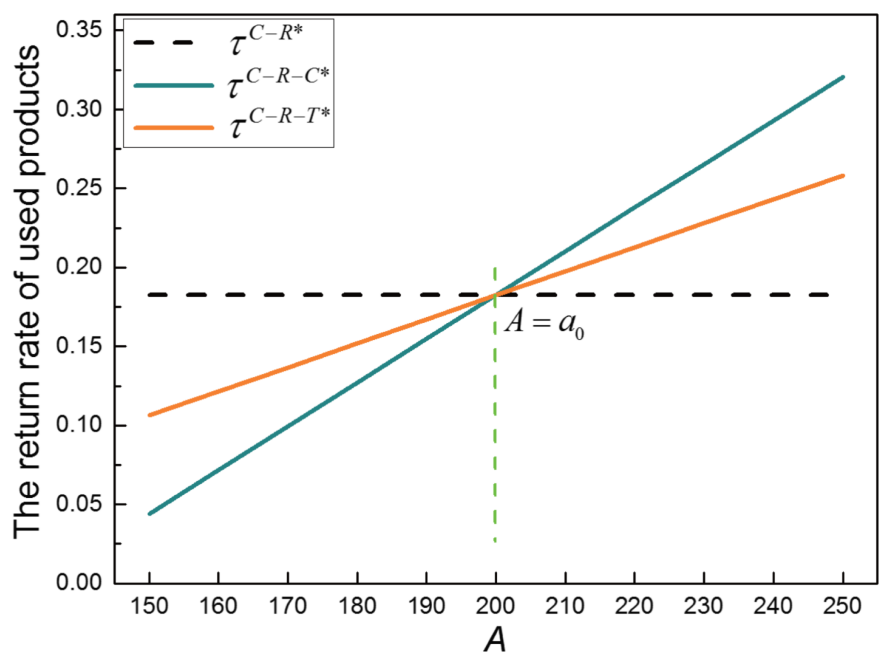

Figure 3. The return rate of used products versus the demand forecast value $(A)$.

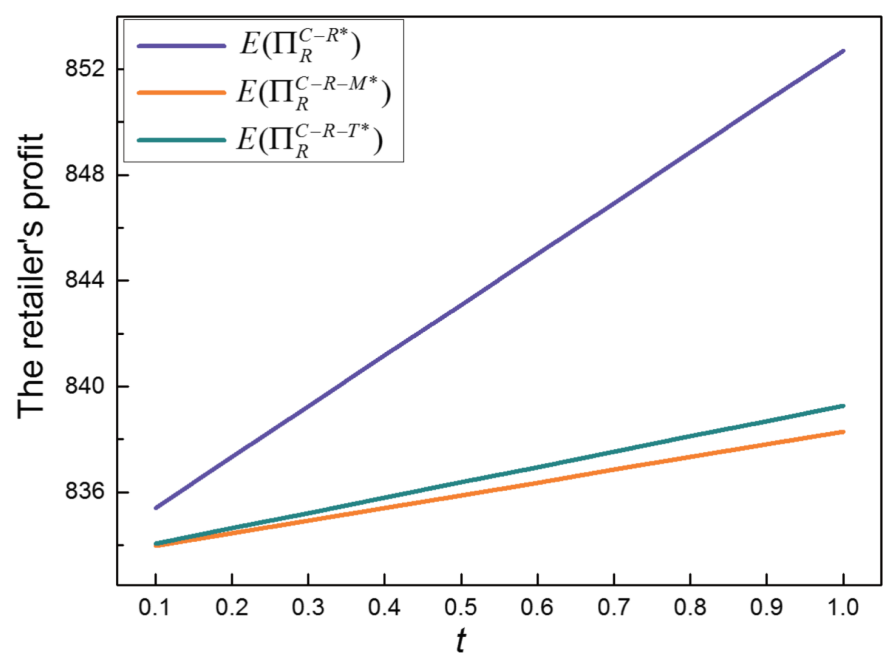

FIGURE 4 . The retailer's profit versus the demand forecast accuracy $(t)$.

chain members. Therefore, some contracts with other chain members and some government subsidies should be implemented to improve the retailer's information sharing behavior [22].

Subsequently, we turn to consider the manufacturer's profit. From Figure 5, the manufacturer's profit has no relevance to the demand forecast accuracy $(t)$ when there is no information sharing in Model $\mathrm{C}-\mathrm{R}$. With the increase of $t$, the manufacturer can make his pricing decisions more accurately in information sharing models. Thus, the higher demand forecast accuracy is, the more profits of the manufacturer in Model $\mathrm{C}-\mathrm{R}-\mathrm{M}$ and Model $\mathrm{C}-\mathrm{R}-\mathrm{T}$ can be achieved. It can be also observed that, the manufacturer's profit in Model $\mathrm{C}-\mathrm{R}-\mathrm{T}$ is more than that in Model $\mathrm{C}-\mathrm{R}-\mathrm{M}$. When both the manufacturer and the collector know larger demand information from the retailer, the collector would like to recycle more used products, which leads to a higher return rate. Under this circumstance, the manufacturer will select an appropriate wholesale price to balance unit price per product 


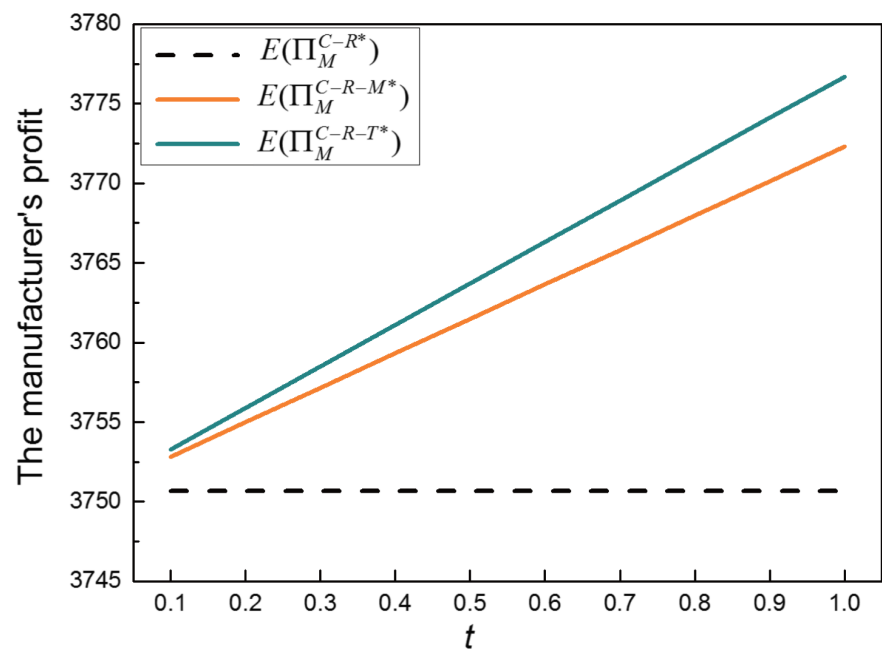

FigURE 5. The manufacturer's profit versus the demand forecast accuracy $(t)$.

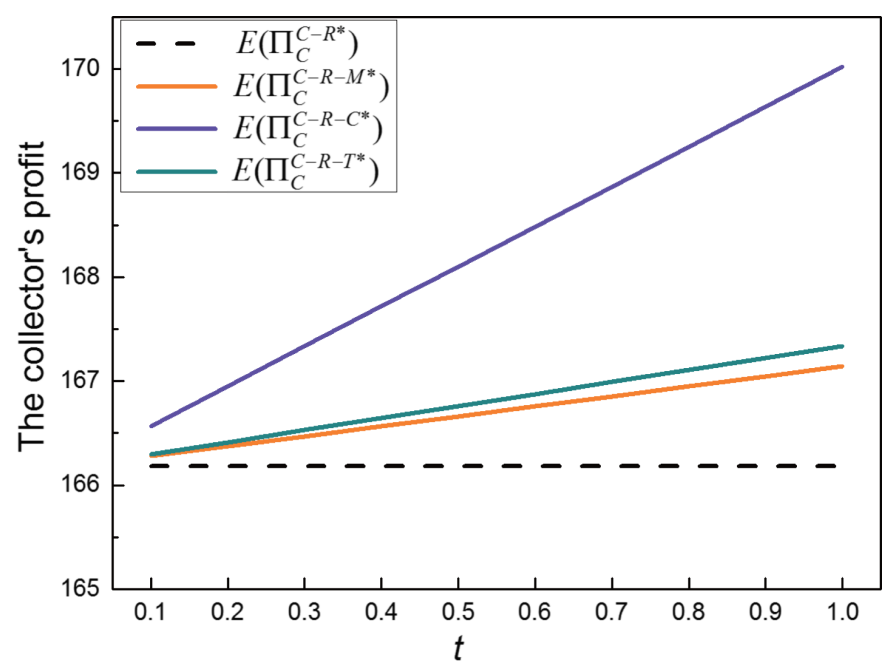

FIGURE 6 . The collector's profit versus the demand forecast accuracy $(t)$.

and the total market demand to earn profits in the forward flow and acquire more used products to extract unit cost savings from remanufacturing in the reverse flow, and eventually maximize his profit.

Figure 6 reveals the evolution of the collector's profits with variant demand forecast accuracy $(t)$. As illustrated from Figure 6, in no information sharing model, the collector's profit remains unchangeable with the increase of demand forecast accuracy. While in information sharing models, the demand forecast accuracy has a positive impact on the collector's profit. Consistent with Corollary 5.6, the collector will reach the largest profit in Model $\mathrm{C}-\mathrm{R}-\mathrm{C}$. This is understandable that, in the case where the retailer only shares demand information with the collector, the collector benefits from both a higher return rate of used products and a larger market demand, which results in the largest profit for the collector. 


\section{Conclusion}

To conclude, we develop four information sharing models in a dual-channel CLSC, namely no information sharing, the retailer sharing information with the manufacturer, the collector and both the manufacturer and the collector, respectively. We examine the impacts of demand forecast value and demand forecast accuracy on pricing decisions and profits of chain members.

This paper yields the following insights. Firstly, the wholesale price and the retail prices of direct and indirect channels gradually increase with the increase of demand forecast value when the retailer shares information with the manufacturer (i.e., with mere the manufacturer and both the manufacturer and the retailer). And the demand forecast value has a positive impact on the return rate of used products in two cases: the retailer reveals information to the collector and the retailer discloses information to the manufacturer and the collector. Moreover, when the demand forecast value exceeds the certain demand (i.e., $A>a_{0}$ ), the wholesale price and the retail prices achieve the largest in Model $\mathrm{C}-\mathrm{R}-\mathrm{M}$, and the return rate of used products is the highest in Model C-R-C.

Secondly, each chain member always obtains more profits with the increase of demand forecast accuracy. From the perspective of the retailer, his profit in the case of the retailer only sharing information with the collector is equivalent to that in the case of no information sharing. And he will suffer a profit loss when the retailer reveals information to the manufacturer (i.e., to mere the manufacturer and both the manufacturer and the retailer). Specifically, the largest profit loss will be achieved in the case of only the manufacturer receiving the demand information because of the larger wholesale price and the smaller market demand. In practice, related government subsidies and some contracts with other chain members should be implemented to improve the retailer's information sharing behavior. Regarding the collector, since the return rate and market demand are larger in Model $\mathrm{C}-\mathrm{R}-\mathrm{C}$ than other models, the collector prefers the case of the retailer only shares information with the collector.

Furthermore, as for the manufacturer, information sharing can bring a profit increase for the manufacturer. And the manufacturer's profit can reach the largest when the retailer simultaneously shares information with the manufacturer and the collector. In this case, the manufacturer, as the channel leader, will set an appropriate wholesale price to balance unit price per product and the total market demand to earn more profits from selling activities in the forward flow and obtain more used products to extract unit cost savings from remanufacturing in the reverse flow, and eventually maximize his profit.

Afterward, we further present some limitations and further research directions. This paper assumes that new and remanufactured products are treated in the same price and market. In fact, the remanufactured products might not achieve required quality specifications and are sold with a lower price. Therefore, an extension of this assumption would be to examine the different prices of new and remanufactured products. Another direction concerns horizontal information sharing, a comprehensive consideration about many retailers simultaneously sharing demand and cost information should also be valuable to investigate.

\section{Appendix A.}

Proof of Proposition 4.2. Taking the second-order derivatives of $E\left(\Pi_{R}^{\mathrm{C}-\mathrm{R}}\right)$ and $E\left(\Pi_{C}^{\mathrm{C}-\mathrm{R}}\right)$ with respect to $p_{r}$ and $\tau$, respectively. And then we can acquire that $\partial^{2} E\left(\Pi_{R}^{\mathrm{C}-\mathrm{R}}\right) / \partial p_{r}^{2}=-2(\beta+\gamma)<0$ and $\partial^{2} E\left(\Pi_{C}^{\mathrm{C}-\mathrm{R}}\right) / \partial \tau^{2}=$ $-2 C_{L}<0$. Therefore, $E\left(\Pi_{R}^{\mathrm{C}-\mathrm{R}}\right)$ is strictly concave in $p_{r}$ and $E\left(\Pi_{C}^{\mathrm{C}-\mathrm{R}}\right)$ is concave in $\tau$.

And the optimal price strategies can be solved as follows:

$$
\begin{aligned}
\partial E\left(\Pi_{R}^{\mathrm{C}-\mathrm{R}}\right) / \partial p_{r} & =(\beta+\gamma) w+A-2(\beta+\gamma) p_{r}+\gamma p_{d}=0, \\
\partial E\left(\Pi_{C}^{\mathrm{C}-\mathrm{R}}\right) / \partial \tau & =b\left(a_{0}-\beta p_{r}\right)-2 C_{L} \tau=0 .
\end{aligned}
$$


Afterward, taking the second-order partial derivatives of $E\left(\Pi_{M}^{\mathrm{C}-\mathrm{R}}\right)$ with respect to $w$ and $p_{d}$, we have the Hessian matrix

$$
\begin{aligned}
H_{M}^{\mathrm{C}-\mathrm{R}} & =\left(\begin{array}{cc}
-(\beta+\gamma)+\frac{(\Delta-b) b \beta^{2}}{4 C_{L}} & \gamma+\frac{(\Delta-b) b \beta^{2} \gamma}{4 C_{L}(\beta+\gamma)} \\
\gamma+\frac{(\Delta-b) b \beta^{2} \gamma}{4 C_{L}(\beta+\gamma)} & -\frac{\gamma(2 \beta+\gamma)}{(\beta+\gamma)}+\frac{(\Delta-b) b \beta^{2} \gamma^{2}}{4 C_{L}(\beta+\gamma)^{2}}
\end{array}\right), \\
& =\frac{\beta \gamma\left[4 C_{L}(\beta+\gamma)-(\Delta-b) b \beta(\beta+2 \gamma)\right]}{2 C_{L}(\beta+\gamma)}>0 .
\end{aligned}
$$

As $\partial^{2} E\left(\Pi_{M}^{\mathrm{C}-\mathrm{R}}\right) / \partial w^{2}=-(\beta+\gamma)+\frac{(\Delta-b) b \beta^{2}}{4 C_{L}}<0$ and $\left|H_{M}^{\mathrm{C}-\mathrm{R}}\right|>0, \quad E\left(\Pi_{M}^{\mathrm{C}-\mathrm{R}}\right)$ is jointly concave in $w$ and $p_{d}$. And then the first-order partial derivatives of $E\left(\Pi_{M}^{\mathrm{C}-\mathrm{R}}\right)$ with respect to $w$ and $p_{d}$ can be described in the following:

$$
\left\{\begin{array}{l}
\frac{\partial E\left(\Pi_{M}^{\mathrm{C}-\mathrm{R}}\right)}{\partial w}=\frac{a_{0}+2 \gamma p_{d}-2(\beta+\gamma) w+\beta c_{n}}{2}-(\Delta-b) \beta b \frac{(\beta+2 \gamma) a_{0}-\beta \gamma p_{d}-\beta(\beta+\gamma) w}{4 C_{L}(\beta+\gamma)}=0 \\
\frac{\partial E\left(\Pi_{M}^{\mathrm{C}-\mathrm{R}}\right)}{\partial p_{d}}=\gamma \frac{a_{0}+2(\beta+\gamma) w-2(2 \beta+\gamma) p_{d}+\beta c_{n}}{2(\beta+\gamma)}-(\Delta-b) b \beta \gamma \frac{(\beta+2 \gamma) a_{0}-\beta \gamma p_{d}-\beta(\beta+\gamma) w}{4 C_{L}(\beta+\gamma)^{2}}=0
\end{array} .\right.
$$

Proof of Proposition 4.4. The second-order derivatives of $E\left(\Pi_{R}^{\mathrm{C}-\mathrm{R}-\mathrm{M}}\right)$ and $E\left(\Pi_{C}^{\mathrm{C}-\mathrm{R}-\mathrm{M}}\right)$ are $\partial^{2} E\left(\Pi_{R}^{\mathrm{C}-\mathrm{R}-\mathrm{M}}\right) / \partial p_{r}^{2}=-2(\beta+\gamma)<0$ and $\partial^{2} E\left(\Pi_{C}^{\mathrm{C}-\mathrm{R}-\mathrm{M}}\right) / \partial \tau^{2}=-2 C_{L}<0$, thus we can get that $E\left(\Pi_{R}^{\mathrm{C}-\mathrm{R}-\mathrm{M}}\right)$ and $E\left(\Pi_{C}^{\mathrm{C}-\mathrm{R}-\mathrm{M}}\right)$ are strictly concave in $p_{r}$ and $\tau$, respectively.

Taking the first-order derivatives of $E\left(\Pi_{R}^{\mathrm{C}-\mathrm{R}-\mathrm{M}}\right)$ with respect to $p_{r}$, we can obtain $\partial E\left(\Pi_{R}^{\mathrm{C}-\mathrm{R}-\mathrm{M}}\right) / \partial p_{r}=$ $(\beta+\gamma) w+A-2(\beta+\gamma) p_{r}+\gamma p_{d}=0$. Therefore, the retail price of indirect channel can be given by $p_{r}^{\mathrm{C}-\mathrm{R}-\mathrm{M}^{*}}=$ $\left[(\beta+\gamma) w+A+\gamma p_{d}\right] / 2(\beta+\gamma)$.

Since the retailer only reveals demand information to the manufacturer in Model $\mathrm{C}-\mathrm{R}-\mathrm{M}$, the expected retail price of indirect channel for the collector is $p_{r}^{\mathrm{C}-\mathrm{R}-\mathrm{M}^{* *}}=\left[(\beta+\gamma) w+a_{0}+\gamma p_{d}\right] / 2(\beta+\gamma)$.

Taking the first-order derivative of $E\left(\Pi_{C}^{\mathrm{C}-\mathrm{R}-\mathrm{M}}\right)$ with respect to $\tau$, the optimalprice strategy can be obtained as follows: $\partial E\left(\Pi_{C}^{\mathrm{C}-\mathrm{R}-\mathrm{M}}\right) / \partial \tau=b\left(a_{0}-\beta p_{r}\right)-2 C_{L} \tau=0$.

Subsequently, taking the second-order partial derivatives of $E\left(\Pi_{M}^{\mathrm{C}-\mathrm{R}-\mathrm{M}}\right)$ with respect to $w$ and $p_{d}$, the Hessian matrix of $E\left(\Pi_{M}^{\mathrm{C}-\mathrm{R}-\mathrm{M}}\right)$ is as follows:

$$
\begin{aligned}
H_{M}^{\mathrm{C}-\mathrm{R}-\mathrm{M}} & =\left(\begin{array}{cc}
-(\beta+\gamma)+\frac{(\Delta-b) b \beta^{2}}{4 C_{L}} & \gamma+\frac{(\Delta-b) b \beta^{2} \gamma}{4 C_{L}(\beta+\gamma)} \\
\gamma+\frac{(\Delta-b) b \beta^{2} \gamma}{4 C_{L}(\beta+\gamma)} & -\frac{\gamma(2 \beta+\gamma)}{(\beta+\gamma)}+\frac{(\Delta-b) b \beta^{2} \gamma^{2}}{4 C_{L}(\beta+\gamma)^{2}}
\end{array}\right) \\
& =\frac{\beta \gamma\left[4 C_{L}(\beta+\gamma)-(\Delta-b) b \beta(\beta+2 \gamma)\right]}{2 C_{L}(\beta+\gamma)}>0 .
\end{aligned}
$$

Therefore, $E\left(\Pi_{M}^{\mathrm{C}-\mathrm{R}-\mathrm{M}}\right)$ is jointly concave in $w$ and $p_{d}$. Then the optimal price strategies can be solved as:

$$
\left\{\begin{array}{l}
\frac{\partial E\left(\Pi_{M}^{\mathrm{C}-\mathrm{R}-\mathrm{M}}\right)}{\partial w}=\frac{A+2 \gamma p_{d}-2(\beta+\gamma) w+\beta c_{n}}{2}-(\Delta-b) b \beta \frac{(\beta+2 \gamma)(A+a)-2 \beta \gamma p_{d}-2 \beta(\beta+\gamma) w}{8 C_{L}(\beta+\gamma)}=0 \\
\frac{\partial E\left(\Pi_{M}^{\mathrm{C}-\mathrm{R}-\mathrm{M}}\right)}{\partial p_{d}}=\frac{\gamma\left[A+2(\beta+\gamma) w-2(2 \beta+\gamma) p_{d}+\beta c_{n}\right]}{2(\beta+\gamma)}-(\Delta-b) b \beta \gamma \frac{(\beta+2 \gamma)(A+a)-2 \beta \gamma p_{d}-2 \beta(\beta+\gamma) w}{8 C_{L}(\beta+\gamma)^{2}}=0
\end{array} .\right.
$$

Proof of Propositions 4.6 and 4.8. Proof of Propositions 4.6 and 4.8 is similar to that of Proposition 4.4. 
Proof of Corollary 5.1. Proof of Corollary 5.1. If $A>a_{0}$ holds, then

$$
\begin{aligned}
w^{\mathrm{C}-\mathrm{R}-\mathrm{M}^{*}}-w^{\mathrm{C}-\mathrm{R}-\mathrm{T}^{*}} & =\frac{\Delta^{2}(\beta+2 \gamma)\left(A-a_{0}\right)}{2\left[16 C_{\iota}(\beta+\gamma)-\beta \Delta^{2}(\beta+2 \gamma)\right]}>0, \\
w^{\mathrm{C}-\mathrm{R}-\mathrm{T}^{*}}-w^{\mathrm{C}-\mathrm{R}-\mathrm{C}^{*}} & =\frac{\left[8 C_{t}(\beta+\gamma)-\Delta^{2}(\beta+2 \gamma) \beta\right]\left(A-a_{0}\right)}{\beta\left[16 C_{\iota}(\beta+\gamma)-\Delta^{2} \beta(\beta+2 \gamma)\right]}>0, \\
w^{\mathrm{C}-\mathrm{R}-\mathrm{C}^{*}}-w^{\mathrm{C}-\mathrm{R}^{*}} & =0 .
\end{aligned}
$$

Hence, we can get $w^{\mathrm{C}-\mathrm{R}-\mathrm{M}^{*}}>w^{\mathrm{C}-\mathrm{R}-\mathrm{T}^{*}}>w^{\mathrm{C}-\mathrm{R}-\mathrm{C}^{*}}=w^{\mathrm{C}-\mathrm{R}^{*}}$. Similarly, we can obtain that $p_{d}^{\mathrm{C}-\mathrm{R}-\mathrm{M}^{*}}>$ $p_{d}^{\mathrm{C}-\mathrm{R}-\mathrm{T}^{*}}>p_{d}^{\mathrm{C}-\mathrm{R}-\mathrm{C}^{*}}=p_{d}^{\mathrm{C}-\mathrm{R}^{*}}$ and $p_{r}^{\mathrm{C}-\mathrm{R}-\mathrm{M}^{*}}>p_{r}^{\mathrm{C}-\mathrm{R}-\mathrm{T}^{*}}>p_{r}^{\mathrm{C}-\mathrm{R}-\mathrm{C}^{*}}=p_{r}^{\mathrm{C}-\mathrm{R}^{*}}$.

Proof of Corollary 5.2. Proof of Corollary 5.2 is similar to that of Corollary 5.1.

Proof of Corollary 5.3. Considering the following equations: and

$$
\begin{aligned}
\tau^{\mathrm{C}-\mathrm{R}-\mathrm{C}^{*}}-\tau^{\mathrm{C}-\mathrm{R}-\mathrm{T}^{*}} & =\frac{\Delta(\beta+2 \gamma)\left[8 C_{L}(\beta+\gamma)-\Delta^{2} \beta(\beta+2 \gamma)\right]\left(A-a_{0}\right)}{8 C_{L}(\beta+\gamma)\left[16 C_{L}(\beta+\gamma)-\Delta^{2} \beta(\beta+2 \gamma)\right]}, \\
\tau^{\mathrm{C}-\mathrm{R}-\mathrm{T}^{*}}-\tau^{\mathrm{C}-\mathrm{R}-\mathrm{M}^{*}} & =\frac{\Delta(\beta+2 \gamma)\left(A-a_{0}\right)}{\left[16 C_{L}(\beta+\gamma)-\Delta^{2} \beta(\beta+2 \gamma)\right]} \\
\tau^{\mathrm{C}-\mathrm{R}-\mathrm{M}^{*}}-\tau^{\mathrm{C}-\mathrm{R}^{*}} & =0 .
\end{aligned}
$$

Thus, if $A>a_{0}$ is satisfied, we can attain that $\tau^{\mathrm{C}-\mathrm{R}-\mathrm{C}^{*}}>\tau^{\mathrm{C}-\mathrm{R}-\mathrm{T}^{*}}>\tau^{\mathrm{C}-\mathrm{R}-\mathrm{M}^{*}}=\tau^{\mathrm{C}-\mathrm{R}^{*}}$.

Proof of Corollary 5.4. Proof of Corollary 5.4 is similar to that of Corollary 5.3.

Proof of Corollary 5.5. (i) To prove $E\left(\Pi_{R}^{\mathrm{C}-\mathrm{R}-\mathrm{M}^{*}}\right)<E\left(\Pi_{R}^{\mathrm{C}-\mathrm{R}-\mathrm{T}^{*}}\right)$, then we examine that

$$
E\left(\Pi_{R}^{\mathrm{C}-\mathrm{R}-\mathrm{M}^{*}}\right)-E\left(\Pi_{R}^{\mathrm{C}-\mathrm{R}-\mathrm{T}^{*}}\right)=\frac{(\beta+2 \gamma) k t}{8 \beta(\beta+\gamma)}-\frac{2 C_{L}(\beta+2 \gamma) k t}{\beta\left[16 C_{L}(\beta+\gamma)-\Delta^{2} \beta(\beta+2 \gamma)\right]}<0 .
$$

After simplification, this reduces to showing that

$$
\left[16 C_{L}(\beta+\gamma)-\Delta^{2} \beta(\beta+2 \gamma)\right]<16 C_{L}(\beta+\gamma) .
$$

Then we can obtain $E\left(\Pi_{R}^{\mathrm{C}-\mathrm{R}-\mathrm{M}^{*}}\right)<E\left(\Pi_{R}^{\mathrm{C}-\mathrm{R}-\mathrm{T}^{*}}\right)$.

Similarly, we can prove $E\left(\Pi_{R}^{\mathrm{C}-\mathrm{R}-\mathrm{T}^{*}}\right)<E\left(\Pi_{R}^{\mathrm{C}-\mathrm{R}-\mathrm{C}^{*}}\right)$ and $E\left(\Pi_{R}^{\mathrm{C}-\mathrm{R}-\mathrm{C}^{*}}\right)=E\left(\Pi_{R}^{\mathrm{C}-\mathrm{R}^{*}}\right)$.

(ii) $\mathrm{As}$

Therefore, $E\left(\Pi_{R}^{\mathrm{C}-\mathrm{R}-\mathrm{M}^{*}}\right)<E\left(\Pi_{R}^{\mathrm{C}-\mathrm{R}-\mathrm{T}^{*}}\right)<E\left(\Pi_{R}^{\mathrm{C}-\mathrm{R}-\mathrm{C}^{*}}\right)=E\left(\Pi_{R}^{\mathrm{C}-\mathrm{R}^{*}}\right)$.

$$
\begin{aligned}
E\left(\Pi_{R}^{\mathrm{C}-\mathrm{R}^{*}}\right) & =\frac{k t}{4(\beta+\gamma)}+\frac{C_{L}^{2}(\beta+\gamma)\left(a_{0}-\beta c_{n}\right)^{2}}{\left[4 C_{L}(\beta+\gamma)-(\Delta-b) b \beta(\beta+2 \gamma)\right]^{2}}, \\
E\left(\Pi_{R}^{\mathrm{C}-\mathrm{R}-\mathrm{M}^{*}}\right) & =\frac{k t}{16(\beta+\gamma)}+\frac{C_{L}^{2}(\beta+\gamma)\left(a_{0}-\beta c_{n}\right)^{2}}{\left[4 C_{L}(\beta+\gamma)-(\Delta-b) \beta b(\beta+2 \gamma)\right]^{2}}, \\
E\left(\Pi_{R}^{\mathrm{C}-\mathrm{R}-\mathrm{C}^{*}}\right) & =\frac{k t}{4(\beta+\gamma)}+\frac{C_{L}^{2}(\beta+\gamma)\left(a_{0}-\beta c_{n}\right)^{2}}{\left[4 C_{L}(\beta+\gamma)-(\Delta-b) b \beta(\beta+2 \gamma)\right]^{2}} .
\end{aligned}
$$


TABLE A.1. The optimal wholesale price in four information sharing models.

\begin{tabular}{ll}
\hline \hline Model & $w^{*}$ \\
$\mathrm{C}-\mathrm{R}$ & $w^{\mathrm{C}-\mathrm{R}^{*}}=\frac{\left[8 C_{L}(\beta+\gamma)-\Delta^{2}(\beta+2 \gamma) \beta\right] a+8 C_{L}(\beta+\gamma) \beta c_{n}}{\beta\left[16 C_{L}(\beta+\gamma)-\Delta^{2} \beta(\beta+2 \gamma)\right]}$ \\
$\mathrm{C}-\mathrm{R}-\mathrm{M}$ & $w^{\mathrm{C}-\mathrm{R}-\mathrm{M}^{*}}=\frac{\left[16 C_{L}(\beta+\gamma)-\Delta^{2}(\beta+2 \gamma) \beta\right] A-\Delta^{2}(\beta+2 \gamma) \beta a+16 C_{L}(\beta+\gamma) \beta c_{n}}{2 \beta\left[16 C_{L}(\beta+\gamma)-\beta \Delta^{2}(\beta+2 \gamma)\right]}$ \\
$\mathrm{C}-\mathrm{R}-\mathrm{C}$ & $w^{\mathrm{C}-\mathrm{R}-\mathrm{C}^{*}}=\frac{\left[8 C_{L}(\beta+\gamma)-\Delta^{2}(\beta+2 \gamma) \beta\right] a+8 C_{L}(\beta+\gamma) \beta c_{n}}{\beta\left[16 C_{L}(\beta+\gamma)-\Delta^{2} \beta(\beta+2 \gamma)\right]}$ \\
$\mathrm{C}-\mathrm{R}-\mathrm{T}$ & $w^{\mathrm{C}-\mathrm{R}-\mathrm{T}^{*}}=\frac{\left[8 C_{L}(\beta+\gamma)-\Delta^{2}(\beta+2 \gamma) \beta\right] A+8 C_{L}(\beta+\gamma) \beta c_{n}}{\beta\left[16 C_{L}(\beta+\gamma)-\Delta^{2} \beta(\beta+2 \gamma)\right]}$ \\
\hline
\end{tabular}

TABLE A.2. The optimal return rate of used products in four information sharing models.

\begin{tabular}{ll}
\hline \hline Model & $\tau^{*}$ \\
\hline $\mathrm{C}-\mathrm{R}$ & $\tau^{\mathrm{C}-\mathrm{R}^{*}}=\frac{\Delta(\beta+2 \gamma)\left(a-\beta c_{n}\right)}{\left[16 C_{L}(\beta+\gamma)-\Delta^{2} \beta(\beta+2 \gamma)\right]}$ \\
$\mathrm{C}-\mathrm{R}-\mathrm{M}$ & $\tau^{\mathrm{C}-\mathrm{R}-\mathrm{M}^{*}}=\frac{\Delta(\beta+2 \gamma)\left(a-\beta c_{n}\right)}{\left[16 C_{L}(\beta+\gamma)-\Delta^{2} \beta(\beta+2 \gamma)\right]}$ \\
$\mathrm{C}-\mathrm{R}-\mathrm{C}$ & $\frac{\Delta(\beta+2 \gamma)}{8 C_{L}(\beta+\gamma)}\left\{\frac{\left[16 C_{L}(\beta+\gamma)-\Delta^{2} \beta(\beta+2 \gamma)\right] A-\left[8 C_{L}(\beta+\gamma)-\Delta^{2}(\beta+2 \gamma) \beta\right] a-8 C_{L}(\beta+\gamma) \beta c_{n}}{\left[16 C_{L}(\beta+\gamma)-\Delta^{2} \beta(\beta+2 \gamma)\right]}\right\}$ \\
$\mathrm{C}-\mathrm{R}-\mathrm{T}$ & $\tau^{\mathrm{C}-\mathrm{R}-\mathrm{T}^{*}}=\frac{\Delta(\beta+2 \gamma)\left(A-\beta c_{n}\right)}{\left[16 C_{L}(\beta+\gamma)-\Delta^{2} \beta(\beta+2 \gamma)\right]}$ \\
\hline
\end{tabular}

Then we can obtain

$$
\begin{aligned}
& \Delta E\left(\Pi_{R}^{\mathrm{C}-\mathrm{R}-\mathrm{M}^{*}}\right)=E\left(\Pi_{R}^{\mathrm{C}-\mathrm{R}-\mathrm{M}^{*}}\right)-E\left(\Pi_{R}^{\mathrm{C}-\mathrm{R}^{*}}\right)=\frac{k t}{16(\beta+\gamma)}-\frac{k t}{4(\beta+\gamma)}=-\frac{3 k t}{16(\beta+\gamma)}<0, \\
& \Delta E\left(\Pi_{R}^{\mathrm{C}-\mathrm{R}-\mathrm{C}^{*}}\right)=E\left(\Pi_{R}^{\mathrm{C}-\mathrm{R}-\mathrm{C}^{*}}\right)-E\left(\Pi_{R}^{\mathrm{C}-\mathrm{R}^{*}}\right)=0
\end{aligned}
$$

namely, $\quad \Delta E\left(\Pi_{R}^{\mathrm{C}-\mathrm{R}-\mathrm{M}^{*}}\right)<\Delta E\left(\Pi_{R}^{\mathrm{C}-\mathrm{R}-\mathrm{C}^{*}}\right)=0$.

Similarly, we can prove $\Delta E\left(\Pi_{R}^{\mathrm{C}-\mathrm{R}-\mathrm{M}^{*}}\right)<\Delta E\left(\Pi_{R}^{\mathrm{C}-\mathrm{R}-\mathrm{T}^{*}}\right)<\Delta E\left(\Pi_{R}^{\mathrm{C}-\mathrm{R}-\mathrm{C}^{*}}\right)=0$.

Proofs of Corollaries 5.6 and 5.7. Proof of Corollaries 5.6 and 5.7 are similar to that of Corollary 5.5 (Tab. A.1A.3). 
TABLE A.3. The optimal profits in four information sharing models.

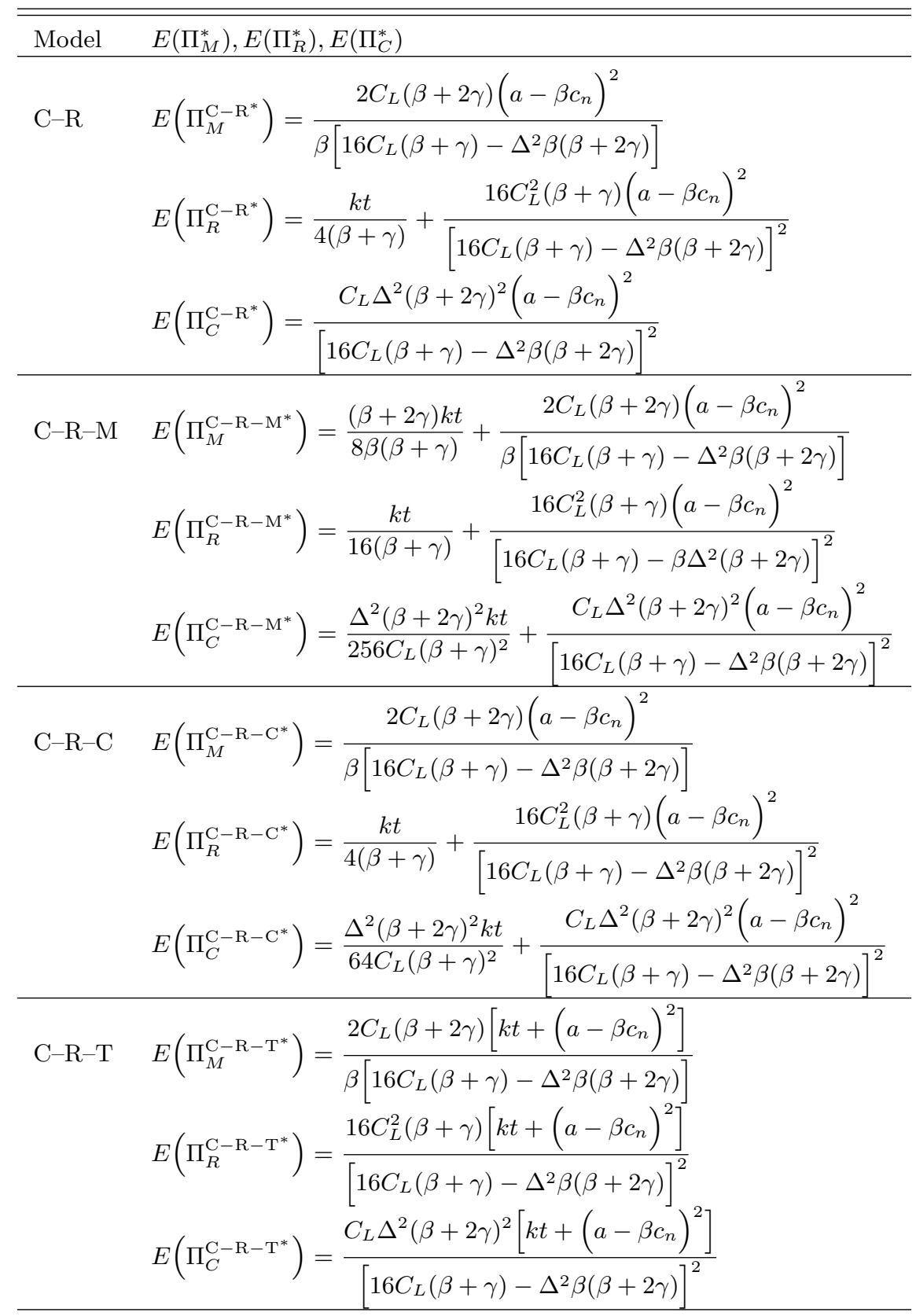

Acknowledgements. This research is supported by National Natural Science Foundation of China under Grant 72001147, Guangdong Planning Project of Philosophy and Social Science of China under Grant GD19YGL18 and the Startup Fund from Shenzhen University under Grants 2019023 and 860-000002110361. 


\section{REFERENCES}

[1] N. Aras, V. Verter and T. Boyaci, Coordination and priority decisions in hybrid manufacturing/remanufacturing systems. Prod. Oper. Manag. 14 (2006) 528-543.

[2] A. Atasu, L.B. Toktay and L.N. Van Wassenhove, How collection cost structure drives a manufacturer's reverse channel choice. Prod. Oper. Manag. 22 (2013) 1089-1102.

[3] D. Chakraborty, T. Garai, K.T. Roy, A three-layer supply chain inventory model for non-instantaneous deteriorating item with inflation and delay in payments in random fuzzy environment. J. Ind. Prod. Eng. 34 (2017) 407-424.

[4] J. Chen, W. Zhang and Z. Liu, Joint pricing, services and quality decisions in a dual-channel supply chain. RAIRO:OR. 54 (2020) 1041-1056.

[5] W.-Y.K. Chiang, D. Chhajed and J.D. Hess, Direct marketing, indirect profits: a strategic analysis of dual-channel supply-chain design. Manag. Sci. 49 (2003) 1-20.

[6] T.-M. Choi, Y. Li and L. Xu, Channel leadership, performance and coordination in closed loop supply chains. Int. J. Prod. Econ. 146 (2013) 371-380.

[7] M.A. Cohen, T.H. Ho and Z.J. Ren, C. Terwiesch, Measuring imputed cost in the semiconductor equipment supply chain. Manag. Sci. 49 (2003) 1653-1670.

[8] A. David and E. Adida, Competition and coordination in a two-channel supply chain. Prod. Oper. Manag. 24 (2015) $1358-1370$.

[9] B. Dan, G. Xu and C. Liu, Pricing policies in a dual-channel supply chain with retail services. Int. J. Prod. Econ. 139 (2012) $312-320$.

[10] P. De Giovanni, P.V. Reddy and G. Zaccour, Incentive strategies for an optimal recovery program in a closed-loop supply chain. Eur. J. Oper. Res. 249 (2016) 605-617.

[11] J. Gaur, M. Amini and A.K. Rao, Closed-loop supply chain configuration for new and reconditioned products: an integrated optimization model. Omega 66 (2017) 212-223.

[12] T. Garai, D. Chakraborty, Fully fuzzy inventory model with price-dependent demand and time varying holding cost under fuzzy decision variables. J. Intell. Fuzzy. Syst. 36 (2019) 3725-3738.

[13] T. Garai, D. Chakraborty, Multi-objective inventory model with both stock-dependent demand rate and holding cost rate under fuzzy random environment. Ann. Data. Sci. 6 (2019) 61-81.

[14] T. Garai, D. Chakraborty, A fuzzy rough multi-objective multi-item inventory model with both stock-dependent demand and holding cost rate. Granular. Comput. 4 (2019) 71-88.

[15] B.C. Giri, A. Chakraborty and T. Maiti, Pricing and return product collection decisions in a closed-loop supply chain with dual-channel in both forward and reverse logistics. J. Manuf. Syst. 42 (2017) 104-123.

[16] V.D.R. Guide and L.N. Van Wassenhove, The evolution of closed-loop supply chain research. Oper. Res. 57 (2009) 10-18.

[17] T. Hosoda, S.M. Disney and S. Gavirneni, The impact of information sharing, random yield, correlation, and lead times in closed loop supply chains. Eur. J. Oper. Res. 246 (2015) 827-836.

[18] G. Hua, S. Wang, T.C.E. Cheng, Price and lead time decisions in dual-channel supply chains. Eur. J. Oper. Res. 205 (2010) $113-126$.

[19] Y. Huang and Z. Wang, Information sharing in a closed-loop supply chain with technology licensing. Int. J. Prod. Econ. 191 (2017) 113-127.

[20] M. Huang, M. Song, L.H. Lee and W.K. Ching, Analysis for strategy of closed-loop supply chain with dual recycling channel. Int. J. Prod. Econ. 144 (2013) 510-520.

[21] K. Govindan, H. Soleimani and D. Kannan, Reverse logistics and closed-loop supply chain: a comprehensive review to explore the future. Eur. J. Oper. Res. 240 (2015) 603-626.

[22] G. Iyer and J.M. Villas-Boas, A bargaining theory of distribution channels. J. Market. Res. 40 (2003) 80-100.

[23] J.-S. Kim and D.-H. Lee, An integrated approach for collection network design, capacity planning and vehicle routing in reverse logistics. J. Oper. Res. Soc. 66 (2015) 76-85.

[24] H.L. Lee, S. Whang, Information sharing in a supply chain. Int. J. Manuf. Technol. Manage. 1 (2000) 79-93.

[25] L. Li, Information sharing in a supply chain with horizontal competition. Manage. Sci. 48 (2002) 1196-1212.

[26] W.-m. Ma, Z. Zhao and H. Ke, Dual-channel closed-loop supply chain with government consumption-subsidy. Eur. J. Oper. Res. 226 (2013) 221-227.

[27] Z. Miao, K. Fu, Z. Xia and Y. Wang, Models for closed-loop supply chain with trade-ins. Omega 66 (2017) $308-326$.

[28] J. Ostlin, E. Sundin and M. Bjorkman, Importance of closed-loop supply chain relationships for product remanufacturing. Int. J. Prod. Econ. 115 (2008) 336-348.

[29] S.Y. Park and H.T. Keh, Modelling hybrid distribution channels: a game-theoretic analysis. J. Retail. Consum. Serv. 10 (2003) 155-167.

[30] S. Saha, S.P. Sarmah and I. Moon, Dual channel closed-loop supply chain coordination with a reward-driven remanufacturing policy. Int. J. Prod. Res. 54 (2015) 1503-1517.

[31] R.C. Savaskan and L.N. Van Wassenhove, Reverse channel design: the case of competing retailers. Manag. Sci. 52 (2006) 1-14.

[32] R.C. Savaskan, S. Bhattacharya, L.N. Van Wassenhove, Closed-loop supply chain models with product remanufacturing. Manag. Sci. 50 (2004) 239-252.

[33] N. Shamir, Strategic information sharing between competing retailers in a supply chain with endogenous wholesale price. Int. J. Prod. Econ. 136 (2012) 352-365. 
[34] N. Shamir and H. Shin, Public forecast information sharing in a market with competing supply chains. Manag. Sci. 62 (2016) 2994-3022.

[35] W. Shang, A.Y. Ha and S. Tong, Information sharing in a supply chain with a common retailer. Manag. Sci. 62 (2015) $245-263$.

[36] G.C. Souza, Closed-loop Supply chains: a critical review, and future research. Decis. Sci. 44 (2013) 7-38.

[37] L. Wang, G.G. Cai, A.A. Tsay and A.J. Vakharia, Design of the reverse channel for remanufacturing: must profit-maximization harm the environment? Prod. Oper. Manag. 8 (2017) 795.

[38] W. Wang, Y. Zhang, Y. Li, Closed-loop supply chains under reward-penalty mechanism: retailer collection and asymmetric information. J. Clean. Prod. 142 (2017) 3938-3955.

[39] J. Xie, L. Liang, L. Liu and P. Ieromonachou, Coordination contracts of dual-channel with cooperation advertising in closedloop supply chains. Int. J. Prod. Econ. 183 (2017) 528-538.

[40] X. Yue and J. Liu, Demand forecast sharing in a dual-channel supply chain. Eur. J. Oper. Res. 174 (2006) $646-667$.

[41] S. Zhang and J. Zhang, Agency selling or reselling: e-tailer information sharing with supplier offline entry. Eur. J. Oper. Res. 280 (2020) 134-151. 